\title{
Parallel Pathways Mediating Both Sound Localization and Gaze Control in the Forebrain and Midbrain of the Barn Owl
}

\author{
Eric I. Knudsen, Phyllis F. Knudsen, and Tom Masino \\ Department of Neurobiology, Stanford University School of Medicine, Stanford, California 94305
}

The hypothesis that sound localization and gaze control are mediated in parallel in the midbrain and forebrain was tested in the barn owl. The midbrain pathway for gaze control was interrupted by reversible inactivation (muscimol injection) or lesion of the optic tectum. Auditory input to the forebrain was disrupted by reversible inactivation or lesion of the primary thalamic auditory nucleus, nucleus ovoidalis (homolog of the medial geniculate nucleus). Barn owls were trained to orient their gaze toward auditory or visual stimuli presented from random locations in a darkened sound chamber. Auditory and visual test stimuli were brief so that the stimulus was over before the orienting response was completed. The accuracy and kinetics of the orienting responses were measured with a search coil attached to the head.

Unilateral inactivation of the optic tectum had immediate and long-lasting effects on auditory orienting behavior. The owls failed to respond on a high percentage of trials when the auditory test stimulus was located on the side contralateral to the inactivated tectum. When they did respond, the response was usually (but not always) short of the target, and the latency of the response was abnormally long. When the auditory stimulus was located on the side ipsilateral to the inactivated tectum, responses were reliable and accurate, and the latency of responses was shorter than normal. In a tectally lesioned animal, response probability and latency to contralateral sounds returned to normal within 2 weeks, but the increase in response error (due to undershooting) persisted for at least 12 weeks.

Despite abnormalities in the response, all of the owls were capable of localizing and orienting to contralateral auditory stimuli on some trials with the optic tectum inactivated or lesioned. This was not true for contralateral visual stimuli. Immediately following tectal inactivation, the owls exhibited complete neglect for visual stimuli located more than $20^{\circ}$ to the contralateral side (i.e., beyond the edge of the visual field of the ipsilateral eye). In the tectally lesioned animal, this neglect diminished with time.

Unilateral inactivation of nucleus ovoidalis had different effects in three owls. Response error to contralateral sound sources increased for one owl and decreased for two; re-

\footnotetext{
Received Sept. 10, 1992; revised Jan. 13, 1993; accepted Jan. 20, 1993.

We thank Masakazu Konishi, Michael Brainard, Joachim Mogdans, and John Olsen for reviewing the manuscript. This work was supported by grants from the NIH: R01 NS 27687-03, R01 DC 00155-13, and T32 NS 07158-12.

Correspondence should be addressed to Eric I. Knudsen, Department of Neurobiology, Fairchild D257, Stanford University School of Medicine, Stanford, CA 94305-5401.

Copyright (C 1993 Society for Neuroscience $0270-6474 / 93 / 132837-16 \$ 05.00 / 0$
}

sponse error to ipsilateral sources did not change significantly for any. The probability of response to ipsilateral (but not contralateral) stimuli decreased for one owl. The latency of response to ipsilateral (but not contralateral) stimuli increased for one and decreased for another. All of the owls, however, routinely localized and oriented toward ipsilateral and contralateral auditory stimuli with nucleus ovoidalis inactivated.

In contrast, when the optic tectum and nucleus ovoidalis were both inactivated unilaterally, the owls no longer oriented toward contralateral auditory stimuli. However, the owls oriented their gaze forward in response to auditory "zeroing" stimuli even when the stimulus was located contralaterally, indicating that they could still hear sounds located contralaterally and could still make contraversive head turns. Thus, the most likely explanation is that they could no longer localize contralateral sound sources. Together, the results demonstrate that both sound localization and the control of gaze can be mediated by distinct parallel pathways in the midbrain and forebrain.

[Key words: auditory localization, orienting behavior, saccades, optic tectum, superior colliculus, auditory cortex]

Both the optic tectum (superior colliculus) and the forebrain have been implicated in sound localization. The optic tectum contains the highest-resolution map of auditory space known anywhere in the brain (Knudsen, 1982; King and Palmer, 1983, Middlebrooks and Knudsen, 1984; King and Hutchings, 1987), and numerous correlations have been reported between the properties of the tectal space map and sound localization behavior (Knudsen, 1982; Jay and Sparks, 1984; Meredith et al., 1987; Stein et al., 1989). Other striking correlations exist between the experience-dependent plasticity of the auditory map in the optic tectum and the plasticity of sound localization behavior (Knudsen, 1985; Knudsen and Brainard, 1991; Knudsen et al., 1991). Nevertheless, the contribution of the optic tectum to sound localization has not been clearly established: lesions of the optic tectum impair auditory localization behavior in some studies (Sprague and Meikle, 1965; Schneider, 1969; Casagrande and Diamond, 1974), but not in others (Thompson and Masterton, 1978; Tunkl, 1980).

In the forebrain, no neurophysiological map of auditory space has been found, yet the forebrain is clearly important to certain aspects of sound localization behavior. Lesions in the auditory forebrain sometimes lead to severe deficits in sound localization in humans (Sanchez-Longo and Forster, 1958; Neff et al., 1975) and can cause deficits in the ability of cats, ferrets, and monkeys to move to the source of a brief sound (Heffner and Masterton, 
1975; Jenkins and Masterton, 1982; Jenkins and Merzenich, 1984; Kavanagh and Kelly, 1987; Heffner and Heffner, 1990). Even with bilateral auditory forebrain lesions, however, most species retain some capacity to localize sound sources (Ravizza and Diamond, 1974; Neff et al., 1975; Kelly, 1980). When considered together, the forebrain and tectal lesion data suggest the hypothesis that, as is true of visual localization, aspects of auditory localization are mediated both by the forebrain and by the optic tectum.

The optic tectum and the forebrain receive auditory spatial information in parallel. The central auditory pathway carries spatial information encoded in frequency-specific, tonotopically organized channels up to the primary auditory areas of the forebrain. However, at the level of the central nucleus of the inferior colliculus (ICc) in the midbrain, a pathway branches off that leads to the optic tectum (Neff et al., 1975; Knudsen, 1983; Knudsen and Knudsen, 1983). This pathway consists of a projection from the ICc to the external nucleus of the IC (ICx), and from there to the optic tectum.

The processing of auditory spatial information along the ICctectal pathway has received much attention. Auditory spatial information from the ICc is combined across frequency channels in the ICx so that neurons become tuned to particular sound source locations (Aitkin et al., 1975, 1984; Knudsen, 1984a; Wagner et al., 1987). In owls, ICx neurons are organized according to their spatial receptive fields to create a map of contralateral auditory space (Knudsen and Konishi, 1978). This map is sharpened in the optic tectum, where it merges with a visual map to create a multimodal representation of the contralateral hemifield (Knudsen, 1982).

The processing and representation of auditory spatial information in the forebrain are less well understood. Neurons in primary auditory projection areas (such as field $\mathrm{L}$ in avians and AI in mammals) are tuned to frequency and many are sensitive to spatial cues. In the primary auditory cortex of cats, neurons sensitive to the same cue cluster together (Imig and Adrian, 1977; Middlebrooks et al., 1980). In the forebrain of owls, some neurons are broadly tuned to frequency and sharply tuned to source location (Knudsen et al., 1977), suggesting either that an integration of spatial information across frequency occurs also in the forebrain of owls, or that space-specific responses generated elsewhere (perhaps along the ICc-tectal pathway) are relayed to the forebrain.

The issue we address here is whether the optic tectum and the forebrain are each capable of subserving sound localization independently of the other. The species studied was the barn owl, a species with highly developed sound localization abilities rivaling those of humans (Knudsen et al., 1979; Makous and Middlebrooks, 1990). The orientation of gaze toward sound sources was used as the behavioral assay, since forebrain or midbrain lesions can cause the expression of more complex behaviors (such as locomotion to the source) to be lost even though the ability to localize sounds persists (Neff et al., 1975). The strategy was to interrupt (by lesion or by pharmacological inactivation) the ICc-tectal pathway at the level of the optic tectum and to interrupt the forebrain pathway at the level of the auditory thalamus, a nucleus called ovoidalis in birds (homologous to the medial geniculate nucleus in mammals). The results demonstrate that interrupting either pathway alone leaves owls still capable of orienting to sound sources. Interrupting both pathways, however, leaves owls capable of hearing, but incapable of orienting to auditory stimuli located on the con- tralateral side. Thus, two distinct pathways, one through the optic tectum and one through the forebrain, can mediate both sound localization and gaze control.

\section{Materials and Methods}

Five tame barn owls (Tyto alba) were used in this study. Each was housed alone so that food intake could be controlled. The birds were trained and tested sequentially over a period of 4 years. Localization deficits were based on the accuracy of orienting responses to free-field sound sources measured before and after unilateral inactivation or lesion of the targeted brain regions.

Testing conditions. Sound localization was measured in a darkened, sound attenuating chamber (Industrial Acoustics Co. 404A), the walls lined with acoustic foam to suppress echoes. Auditory stimuli were generated by a movable, $6 \mathrm{~cm}$ dynamic loudspeaker. The speaker was mounted on a vertical, semicircular track. Stepping motors rotated the track about a vertical axis to change the azimuth of the speaker, and they rolled the track along its length to change the elevation of the speaker. The movement of the speaker defined a sphere $90 \mathrm{~cm}$ in radius. Speaker position was accurate to within $\pm 0.5^{\circ}$.

The auditory test stimulus was a noise burst, $100 \mathrm{msec}$ in duration, with $10 \mathrm{msec}$ rise and fall times. The amplitude (measured free-field) was varied randomly between 20 and $50 \mathrm{~dB}$ SPL. The visual test stimulus was a $250 \mathrm{msec}$ pulse of light from a red, light-emitting diode (LED) that was centered in the speaker cone and traveled with the speaker. A second loudspeaker and LED was used to orient the head to a standard "zero" position at the beginning of each trial. The zeroing speaker and LED were attached to the wall of the sound chamber, in line with the center of the movable speaker when it was positioned at $0^{\circ}$ azimuth (az), $0^{\circ}$ elevation (el)

Measurement of gaze direction. Direction of gaze was measured using a search coil system (C-N-C Engineering). The induction coils were 1.8 $\mathrm{m}$ in diameter and surrounded the speaker-moving system. The search coil attached to a clip that was cemented to the skull; the clip was attached while the animal was anesthetized with halothane and nitrous oxide. Because the eyes of the barn owl are essentially stationary in the head (du Lac and Knudsen, 1990), head orientation indicates the animal's direction of gaze. The search coil system was calibrated daily and the precision of the system was $\pm 0.1^{\circ}$ over the range that was sampled (azimuthal angles up to $80^{\circ}$ and elevational angles up to $30^{\circ}$ ).

Training procedure. Each owl was trained to stand on the perch and to orient toward auditory and visual targets. During initial training, the owl was rewarded for turning toward a sustained auditory or visual stimulus. The reward was a small piece of meat presented from an automated feeder located at the bird's feet. As training progressed, the position of the targets was varied over a wide range and progressively more stringent criteria were placed on the accuracy of the response in order to obtain a reward. After the owl was orienting reliably toward the single stimulus, we introduced the sequential stimulus paradigm the owl was required to fixate first on the zeroing sound or light and then on the test sound or light located at a different position. Once the owl performed this task reliably, the auditory and visual test stimuli were shortened to their standard durations of $100 \mathrm{msec}$ and $250 \mathrm{msec}$, respectively.

Testing procedure. The perch was adjusted so that the owl's head was centered in the coordinate space defined by the speaker-moving system. The lights in the chamber were extinguished. The test speaker was moved to a previously determined location (sound associated with moving the test speaker and LED was unrelated to the final location of the targets). Either the zeroing light or the zeroing loudspeaker was turned on and it remained on until the owl oriented to within $3^{\circ}$ of the stimulus' location. The zeroing stimulus was then turned off and either the 100 msec auditory or the $250 \mathrm{msec}$ visual test stimulus was presented. Simultaneous with test stimulus onset, the computer began sampling head position at $2 \mathrm{msec}$ intervals, and continued collecting samples for $1 \mathrm{sec}$ ( 800 msec for owl 1). Because of their short durations, the stimuli were over often before the head began to move and always before the head completed its movement. When measuring head orientations before and after each lesion/inactivation experiment, the reward was no longer contingent on the accuracy of the response; only no response or a downward turn toward the feeder was unrewarded. After each trial, the stimulus was moved to a new location.

Pharmacological inactivation. Muscimol (Sigma) was used to inactivate the optic tectum and nucleus ovoidalis. Muscimol hyperpolarizes 
nerve cells by activating receptors for $\gamma$-aminobutyric acid (GABA). Consequently, it does not affect fibers of passage. A previous study of the primate optic tectum showed that the effects of muscimol inactivation increase over the first $40 \mathrm{~min}$ following injection and persist for up to $7 \mathrm{hr}$ (Hikosaka and Wurtz, 1985).

Regions of the brain that were to be inactivated with muscimol were targeted electrophysiologically. The methodology for unit recording has been described in detail by Olsen et al. (1989). Briefly, the owls were anesthetized with intramuscular injections of ketamine $\mathrm{HCl}(15 \mathrm{mg} / \mathrm{kg})$ and diazepam $(5 \mathrm{mg} / \mathrm{kg})$, and positioned in a sound chamber that was equipped for free-field and closed-field auditory stimulation and for visual stimulation. Electrodes were positioned stereotaxically. Sites in the optic tectum were spatially tuned for auditory and visual stimuli and were characterized by the location of the visual receptive field (Knudsen, 1982); sites in nucleus ovoidalis responded strongly to tonal stimulation with latencies ranging from 8 to $12 \mathrm{msec}$.

Muscimol was delivered through a 25 gauge stainless steel injector tube coupled by polyethylene tubing to a $1 \mu \mathrm{l}$ Hamilton syringe. The injector tube was directed to the desired site in the brain by an implanted 21 gauge stainless steel guide tube. Guide tubes were implanted in the following manner. A lacquered tungsten microelectrode was attached with wax to the inside of the guide tube so that the tip of the electrode protruded precisely $3 \mathrm{~mm}$ (measured with a compound microscope) beyond the end of the guide tube. The sterilized, guide tube-electrode assembly was lowered into the brain while recording through the electrode. When the tuning properties of unit activity indicated that the electrode was at the desired site, the guide tube was cemented to the skull with dental acrylic. This procedure fixed the end of the guide tube $3 \mathrm{~mm}$ directly above the targeted site. The electrode was then removed and the guide tube was plugged with a 25 gauge stainless steel rod coated with antibiotic ointment. Finally, a protective plastic cylinder $(1 \mathrm{~cm}$ diameter) was cemented over the protruding end of the guide tube.

On the day of an injection, the sterilized, injector tube-syringe assembly was filled with distilled water. Then $100 \mathrm{nl}$ of silicone fluid was drawn into the end of the injector tube, followed by the desired amount of muscimol. The stainless steel rod was removed from the implanted guide tube. The preloaded injector tube was slowly lowered through the guide tube until a collar on the injector tube seated on the guide tube. The collar allowed the injector tube to extend precisely $3 \mathrm{~mm}$ beyond the end of the guide tube when fully inserted. After about $1 \mathrm{~min}$, the premcasurcd muscimol was injectcd over a period of $1 \mathrm{~min}$; a small bubble in the polyethylene tubing verified the advance of fluid. The injector tube was left in place for another minute before being slowly removed. The stainless steel rod, coated with antibiotic ointment, was then replaced in the guide tube. Quantitative behavioral testing began $40 \mathrm{~min}$ after the injection was made and continued for up to $2 \mathrm{hr}$. From three to five muscimol injections were made at each site on different days. Data gathered on different days after equivalent injections are combined in the analyses of the immediate effects of inactivation.

The optic tectum was reversibly inactivated in owls 2,3 , and 5 (Table 1). Guide tubes were implanted so that the tip of the injector tube would be located in the middle of the tectum between the visual representation of $26^{\circ}$ to $32^{\circ}$ contralateral azimuth and $0^{\circ}$ to $-5^{\circ}$ elevation. The standard dosage of muscimol was $1 \mu \mathrm{g}(200 \mathrm{nl} ; 5 \mu \mathrm{g} / \mu \mathrm{l}$ in saline) for owls 2 and 3 and $0.5 \mu \mathrm{g}(100 \mathrm{nl} ; 5 \mu \mathrm{g} / \mu \mathrm{l})$ for owl 5 .

Nucleus ovoidalis was reversibly inactivated in owls 3 and 5 (Table 1). The standard dosage of muscimol was $0.25 \mu \mathrm{g}(50 \mathrm{nl} ; 5 \mu \mathrm{g} / \mu \mathrm{l})$. In the first such experiments, injections of $1 \mu \mathrm{g}$ and $0.5 \mu \mathrm{g}$ were tried on separate days. Because postural abnormalities resulted, no localization data could be collected from these experiments and the dose was reduced.

Lesions. In owl 1, most of the optic tectum was lesioned on the left side (Table 1). This was accomplished with four radiofrequency lesions (Radionics Inc.) placed at $1 \mathrm{~mm}$ intervals along the rostrocaudal length of the tectum.

In owl 4, nucleus ovoidalis was electrolytically lesioned on the left side (Table 1). The lesion was made by passing $100 \mu \mathrm{A}$ of cathodal current for $1 \mathrm{~min}$ through a $0.8 \mathrm{M} \Omega$ tungsten electrode at two sites: 200 $\mu \mathrm{m}$ below the dorsal border of the nucleus and $200 \mu \mathrm{m}$ above the ventral border of the nucleus.

Assessment and maintenance of motivation. The orientation task was a behavior that the owls performed naturally in response to novel stimuli. However, training was required to maintain the accuracy and reliability of the response. Four of the five owls were conditioned to the point that they would orient to within $10^{\circ}$ of the test stimuli on $100 \%$
Table 1. Experimental procedures

\begin{tabular}{lll} 
Owl & Optic tectum & Nucleus ovoidalis \\
\hline 1 & Left: lesioned & \\
2 & Right: muscimol $(1.0 \mu \mathrm{g})$ & \\
& 4 injections & \\
$3^{a}$ & Right: muscimol $(1.0 \mu \mathrm{g})$ & Right: muscimol $(0.25 \mu \mathrm{g})$ \\
& 5 injections & 4 injections \\
4 & Left: muscimol $(1.0 \mu \mathrm{g})$ & Left: lesioned \\
& 3 injections & \\
$5^{b}$ & Right: muscimol $(0.5 \mu \mathrm{g})$ & Right: muscimol $(0.25 \mu \mathrm{g})$ \\
& 4 injections & 4 injections
\end{tabular}

${ }^{a}$ The order of experiments from which data were gathered was C, C, T, C, T, O, C, B, O, C, B, C, T (C, control; T, tectal injection; O, ovoidalis injection; B, injection of tectum and ovoidalis).

${ }^{b}$ The order of experiments from which data were gathered was $\mathrm{C}, \mathrm{C}, \mathrm{O}, \mathrm{T}, \mathrm{C}, \mathrm{B}$, $\mathrm{C}, \mathrm{O}, \mathrm{B}, \mathrm{T}, \mathrm{C}$.

of the trials. The fifth owl (owl 5) responded on only $70 \%$ of the sound trials even after 4 weeks of training. When this bird responded, however, the response was consistently within $10^{\circ}$ of the target. Therefore, we commenced brain inactivation experiments with the bird at this level of performance.

During the behavioral experiments, we assessed motivation on the basis of the accuracy and probability of responses to sounds presented on the side ipsilateral to the lesion or the muscimol injection (the "unaffected" side). After one to three trials on the contralateral side, a sound test stimulus was presented on the ipsilateral side. If the animal failed to respond (a rare occurrence) or responded inaccurately (error greater than $10^{\circ}$ ), the speaker was moved to a new ipsilateral location and the test was repeated. We interpreted no response or inaccurate responses to ipsilateral stimuli on three successive trials as signifying a decrease in motivation: data collection was discontinued and the bird was returned to the aviary. By using this procedure, we attempted to hold motivation at a high and relatively constant level.

Data analysis. A typical test session consisted of 40-80 trials. Head position and stimulus typc and location were stored for each trial. Head position was defined in a double-pole coordinate system (Knudsen, 1982): azimuth indicates degrees left or right of the vertical plane that contained the center of the head and the zeroing light; elevation indicates degrees above or below the horizontal plane that contained the same two points. During testing, stimuli were presented within $15^{\circ}$ of the horizontal plane and only the azimuthal component of the response was analyzed. This essentially collapsed the task into a one-dimensional localization task, and the data reported here refer specifically to the azimuthal component of head position and movement.

Computer programs calculated the starting and final head positions as well as the latency and maximum speed of the movement. The raw position data were smoothed with a Gaussian weighted, centered running average that spanned $14 \mathrm{msec}$. A speed-time profile was calculated from the smoothed data. Movement onset was the time at which speed exceeded 5 degrees/sec; movement termination was the time at which speed dropped below 5 degrees/sec. The following values were extracted: starting head position, the position before movement onset;

final head position, the position at the termination of the movement; stimulus location, the azimuthal position of the stimulus relative to the starting head position;

orientation error, the azimuthal difference between the position of the stimulus and the final head position, quantified in degrees short of $(-)$ or beyond $(+)$ the target;

latency, the time between stimulus onset and movement onset; and maximum speed, the highest horizontal speed attained between movement onset and termination.

Particularly in the earlier experiments (owls 1-3), some data were lost due to failures in data storage. For these trials, starting and final head positions were recorded by hand from a calibrated storage oscilloscope. However, latency and maximum speed could not be recovered. These trials account for discrepancies between sample sizes for response error versus latency and maximum speed.

Histology. After the behavioral tests were completed, owls 2-5 were given lethal doses of sodium pentobarbital. Owls $2-4$ were perfused 
Table 2. Auditory orienting behavior ${ }^{a}$

\begin{tabular}{|c|c|c|c|c|c|c|c|c|c|c|c|c|c|c|c|c|c|c|c|c|c|}
\hline \multirow[b]{3}{*}{ Owl } & \multicolumn{3}{|l|}{ Control ${ }^{\prime}$} & \multicolumn{6}{|c|}{ Tectum inactivated } & \multicolumn{6}{|c|}{ Ovoidalis inactivated } & \multicolumn{6}{|c|}{ Both inactivated } \\
\hline & \multirow{2}{*}{$\begin{array}{l}\text { Error } \\
\text { (degrees) } \\
\bar{X} \text { SD }(n)\end{array}$} & \multirow{2}{*}{$\begin{array}{l}\text { Latencyd } \\
\text { (msec) } \\
\text { med-quart } \\
(n)\end{array}$} & \multirow{2}{*}{$\begin{array}{l}\text { Resp. } \\
\text { prob. } \\
\%(n)\end{array}$} & \multicolumn{2}{|c|}{ Error } & \multicolumn{2}{|c|}{ Latency } & \multicolumn{2}{|c|}{$\begin{array}{l}\text { Resp. } \\
\text { prob. }\end{array}$} & \multicolumn{2}{|c|}{ Error: } & \multicolumn{2}{|l|}{ Latency } & \multicolumn{2}{|l|}{$\begin{array}{l}\text { Resp. } \\
\text { prob. }\end{array}$} & \multicolumn{2}{|c|}{ Error: } & \multicolumn{2}{|c|}{ Latency $y^{d / t}$} & \multicolumn{2}{|c|}{$\begin{array}{l}\text { Resp. } \\
\text { prob. }\end{array}$} \\
\hline & & & & Ipsi & Cont & Ipsi & Cont & Ipsi & Cont & Ipsi & Cont & Ipsi & Cont & Ipsi & Cont & Ipsi & Cont & Ipsi & Cont & Ipsi & Cont \\
\hline 1 & $\begin{array}{c}-5.7 \\
5.0 \\
(39)\end{array}$ & $\begin{array}{l}83 \\
73-104 \\
(36)\end{array}$ & $\begin{array}{l}100 \\
(39)\end{array}$ & $\begin{array}{c}-4.1 \\
5.0 \\
(18)\end{array}$ & $\begin{array}{c}-14.7^{*} \\
7.3 \\
(45)\end{array}$ & $\begin{array}{l}74 \\
64-84 \\
(18)\end{array}$ & $\begin{array}{l}102 \\
75-120 \\
(43)\end{array}$ & $\begin{array}{l}100 \\
(18)\end{array}$ & $\begin{array}{l}100 \\
(45)\end{array}$ & & & & & & & & & & & & \\
\hline 2 & $\begin{array}{r}-2.9 \\
3.2 \\
(50)\end{array}$ & $\begin{array}{l}78 \\
60-101 \\
(45)\end{array}$ & $\begin{array}{l}100 \\
(50)\end{array}$ & $\begin{array}{r}-4.5 \\
2.9 \\
(20)\end{array}$ & $\begin{array}{c}-\mathbf{1 3 . 3 *} \\
19.2 \\
(21)\end{array}$ & $\begin{array}{l}62^{*} \\
46-76 \\
(18)\end{array}$ & $\begin{array}{l}144^{*} \\
82-184 \\
(18)\end{array}$ & $\begin{array}{l}100 \\
(20)\end{array}$ & $\begin{array}{l}70^{*} \\
(30)\end{array}$ & & & & & & & & & & & & \\
\hline 3 & $\begin{array}{c}-3.9 \\
4.2 \\
(73)\end{array}$ & $\begin{array}{l}98 \\
72-125 \\
(69)\end{array}$ & $\begin{array}{l}100 \\
(73)\end{array}$ & $\begin{array}{c}-3.8 \\
4.8 \\
(23)\end{array}$ & $\begin{array}{c}-12.8^{*} \\
8.2 \\
(17)\end{array}$ & $\begin{array}{l}66^{*} \\
50-100 \\
(19)\end{array}$ & $\begin{array}{l}179^{*} \\
112-212 \\
(16)\end{array}$ & $\begin{array}{l}96 \\
(24)\end{array}$ & $\begin{array}{l}61^{*} \\
(28)\end{array}$ & $\begin{array}{l}-6.4 \\
1.5 \\
(5)\end{array}$ & $\begin{array}{c}-0.7^{*} \\
3.0 \\
(12)\end{array}$ & $\begin{array}{l}58^{*} \\
45-88 \\
(4)\end{array}$ & $\begin{array}{l}123 \\
82-144 \\
(10)\end{array}$ & $\begin{array}{r}100 \\
(5)\end{array}$ & $\begin{array}{l}100 \\
(12)\end{array}$ & $\begin{array}{r}-3.5 \\
4.1 \\
(12)\end{array}$ & (2) & $\begin{array}{l}52^{*} \\
50-67 \\
(12)\end{array}$ & & $\begin{array}{l}100 \\
(12)\end{array}$ & $\begin{array}{l}10^{*} \\
(19)\end{array}$ \\
\hline 4 & $\begin{array}{c}-4.2 \\
4.0 \\
(44)\end{array}$ & $\begin{array}{l}98 \\
60-139 \\
(39)\end{array}$ & $\begin{array}{l}100 \\
(44)\end{array}$ & & & & & & & $\begin{array}{c}-5.7 \\
4.4 \\
(14)\end{array}$ & $\begin{array}{c}0.8^{*} \\
5.5 \\
(28)\end{array}$ & $\begin{array}{l}198^{*} \\
143-226 \\
(13)\end{array}$ & $\begin{array}{l}106 \\
74-145 \\
(25)\end{array}$ & $\begin{array}{l}100 \\
(14)\end{array}$ & $\begin{array}{l}100 \\
(28)\end{array}$ & $\begin{array}{c}-3.2 \\
4.8 \\
(17)\end{array}$ & (0) & $\begin{array}{l}79 \\
60-101 \\
(16)\end{array}$ & & $\begin{array}{l}100 \\
(17)\end{array}$ & $0^{*}$ \\
\hline 5 & $\begin{array}{c}-3.4 \\
4.3 \\
(77)\end{array}$ & $\begin{array}{l}91 \\
57-126 \\
(60)\end{array}$ & $\begin{array}{c}70 \\
(110)\end{array}$ & $\begin{array}{c}-3.7 \\
2.8 \\
(41)\end{array}$ & $\begin{array}{c}-7.7^{*} \\
8.8 \\
(28)\end{array}$ & $\begin{array}{l}78 \\
61-87 \\
(32)\end{array}$ & $\begin{array}{l}139^{*} \\
100-208 \\
(20)\end{array}$ & $93^{*}$ & $\begin{array}{l}42^{*} \\
(66)\end{array}$ & $\begin{array}{c}-1.8 \\
4.1 \\
(17)\end{array}$ & $\begin{array}{c}-6.7^{*} \\
5.0 \\
(31)\end{array}$ & $\begin{array}{l}99 \\
88-114 \\
\text { (14) }\end{array}$ & $\begin{array}{l}80 \\
56-104 \\
(26)\end{array}$ & $43^{*}$ & (37) & $\begin{array}{c}-\mathbf{3 . 3} \\
3.4 \\
(24)\end{array}$ & (2) & $\begin{array}{l}80 \\
56-94 \\
(21)\end{array}$ & & $\begin{array}{l}92^{*} \\
(26)\end{array}$ & (31) \\
\hline
\end{tabular}

${ }^{a}$ These data are from " $\mathrm{k} e$ subset of trials in which the auditory test stimulus was located between $20^{\circ}$ and $40^{\circ}$ contralateral (cont) or between $20^{\circ}$ and $40^{\circ}$ ipsilateral (ipsi).

"These data were gathered after guide tubes had been implanted. Data for responses to the left and right were the same for each owl, and were combined.

"Negative values indicate final orientations were short of the target.

${ }^{d}$ Latencies were not randomly distributed and therefore are represented by medians (med) and quartiles (quart).

- Docs not include data from trials in which no movement or a downward movement was made. ANOVA was used to compare these data with control data. The criterion for significance $\left(^{*}\right)$ was $p<0.05$.

Mann-Whitney $U$ test was used to compare these data with control data. The criterion for significance $\left(^{*}\right)$ was $p<0.05(z>0.475)$.

${ }^{8} \chi^{2}$ was used to compare these data with control data. The criterion for significance $\left({ }^{*}\right)$ was $p<0.05\left(\chi^{2}>3.841\right.$, $\left.\mathrm{df}=1\right)$.

through the heart with formalin; owl 5 was perfused with $1 \%$ paraformaldehyde, $1.25 \%$ glutaraldehyde, and $5 \%$ sucrose in $0.1 \mathrm{~m}$ phosphate buffer. Owl 1 died; its brain was immersed in formalin postmortem and processed after 4 weeks of fixation. Brains were blocked and sectioned in the transverse plane, perpendicular to the animal's visual plane (Knudsen, 1982). Mounted sections were stained with cresyl violet and lesioned areas werc rcconstructed, using a camcra lucida, and photographed.

\section{Results}

\section{Control performance}

Control data were collected from the five owls after injection guide tubes had been implanted; for owls 3 and 5, control experiments were interleaved with the different kinds of inactivation experiments (Table 1 notes). Control data, which appear in Table 2 and in figures throughout the article, can be summarized as follows. Response to a brief auditory or visual stimulus consisted of a rapid rotation of the head (head saccade) followed by a steady fixation. The probability of response to a given stimulus was close to $100 \%$ for all owls except owl 5 , which responded on only $70 \%$ of the auditory trials. The owls oriented the head usually to within a few degrees of auditory and visual targets, orientation errors being due primarily to a consistent undershoot of the target in azimuth (Fig. 1 $A, B$ ); for each owl, there was no significant difference (two-tailed $t$ test, $p=0.05$ level) in the orientation errors for responses to the left and right sides. Median response latencies to auditory stimuli were $78-98 \mathrm{msec}$. Median response latencies to visual stimuli were considerably longer and more variable across the five owls, ranging from 156 up to $392 \mathrm{msec}$. The maximum speed attained during a movement increased with the size of the movement, and was approximately equal for auditory and visual responses of equivalent size (Fig. 1C).

\section{Performance after tectal inactivation with muscimol}

Muscimol injection sites in the optic tectum of owls 2, 3, and 5 are shown in Figure 2. In owl 3 (Fig. 2B), the injections were centered in the deep layers (layers 13-15). The pattern of tissue damage at the injection site indicated that muscimol probably entered the tectal ventricle. If so, the muscimol would have inactivated not only the optic tectum, but also neurons in the ICx and the superficial nucleus (ICs) that border on the ventricle. Thus, the behavioral data from owl 3 on the effects of tectal inactivation probably include the effects of ICX and ICs inactivation as well. In owls 2 and 5 (Fig. $2 A, C$ ), the tectal injection sites were centered in the superficial layers (layers 1-10), and therefore the probability that the injections affected cells in the IC is less. In all 3 owls, the injection sites were centered along the rostrocaudal axis of the tectum.

Within 20 min of making an injection of muscimol into the optic tectum on one side, the following qualitative changes in orientation behavior were observed. The owls began making frequent ipsiversive (relative to the side of the injection) head saccades with no apparent provocation. No spontaneous contraversive saccades were observed. Repeated ipsiversive saccades occasionally caused the entire body to turn around on the perch $(1.25 \mu \mathrm{g}$ of muscimol injected once into owl 2 caused persistent turning on the perch and prevented measurements from being made). The head tended to remain deviated toward the ipsilateral side and to drift slowly toward the contralateral side whenever saccades were not being made and the animal was not attending to a stimulus. Orientation responses were not made either to tactile stimulation of the contralateral face or body, or to looming visual stimuli brought to within a few millimeters of the cornea on the contralateral side; even very 
A

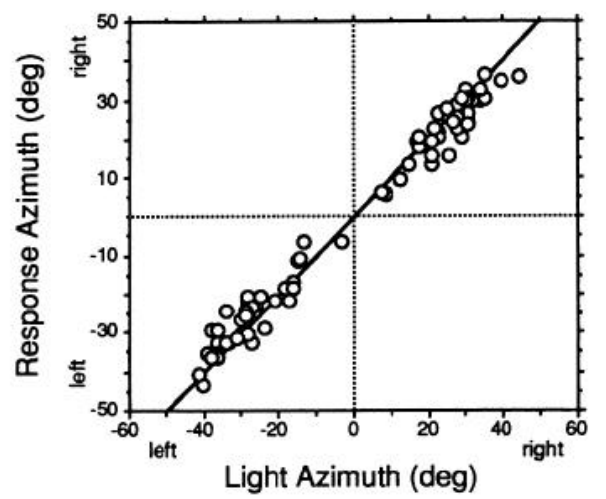

B

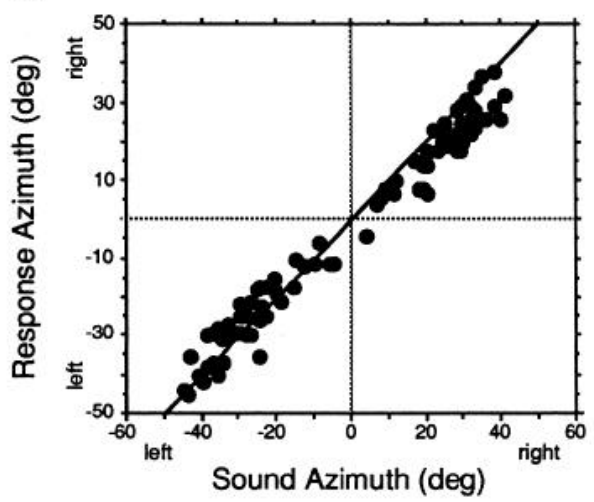

C

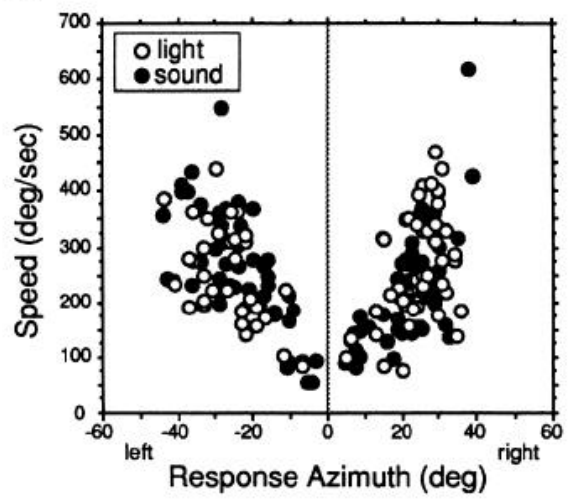

Figure 1. Control responses to visual and auditory stimuli. The data are from owl 3. A, Final head orientation is plotted as a function of visual stimulus (LED) location. The diagonal line represents perfect accuracy. B, Final head orientation versus auditory stimulus (loudspeaker) location. $C$, Speed of movement in response to visual (open symbols) and auditory (solid symbols) stimuli plotted as a function of the magnitude of the orienting movement.

bright flashes of light presented on the contralateral side in a dark room elicited no response. However, contraversive head turns were elicited occasionally in response to contralateral auditory stimuli. All such stimuli, when presented on the ipsilateral side, elicited either an orienting or a startle response.

Trained orienting behavior was tested beginning $40 \mathrm{~min}$ after an injection. Because of the contralateral visual neglect described above, when the zeroing light was used, it had to be left on until the owl turned its head spontaneously so that the light source was in the frontal or ipsilateral portion of the visual field before the owl would zero the head. In contrast, the owls zeroed the head immediately in response to the zeroing sound regardless of its direction relative to the head. This response did not necessarily reflect localization of the sound stimulus: due to extensive training, the owls would often wait for a trial to begin with the head already in or near the zero position, and they may have responded to the zeroing sound simply by positioning the head relative to the body in this zero position.

Responses to the sound and light test stimuli were apparently normal as long as the test stimulus was located in the hemifield ipsilateral to the inactivated tectum (Fig. $3 A, B$ ). Therefore, responses to ipsilateral stimuli were used to monitor motivation (see Materials and Methods).

The spatial extent of contralateral visual neglect served as a useful assay of the effective spread of muscimol. Each tectum receives visual (and auditory) input that represents stimuli located in the contralateral hemifield and nearly $20^{\circ}$ into the ipsilateral hemifield (corresponding to the nasal edge of the visual field of the contralateral eye; Knudsen, 1982). The injections were made in the middle of the tectum, approximately in the region of the map where neurons were tuned to stimuli located at $30^{\circ}$ contralateral azimuth and $0^{\circ}$ elevation (see Materials and
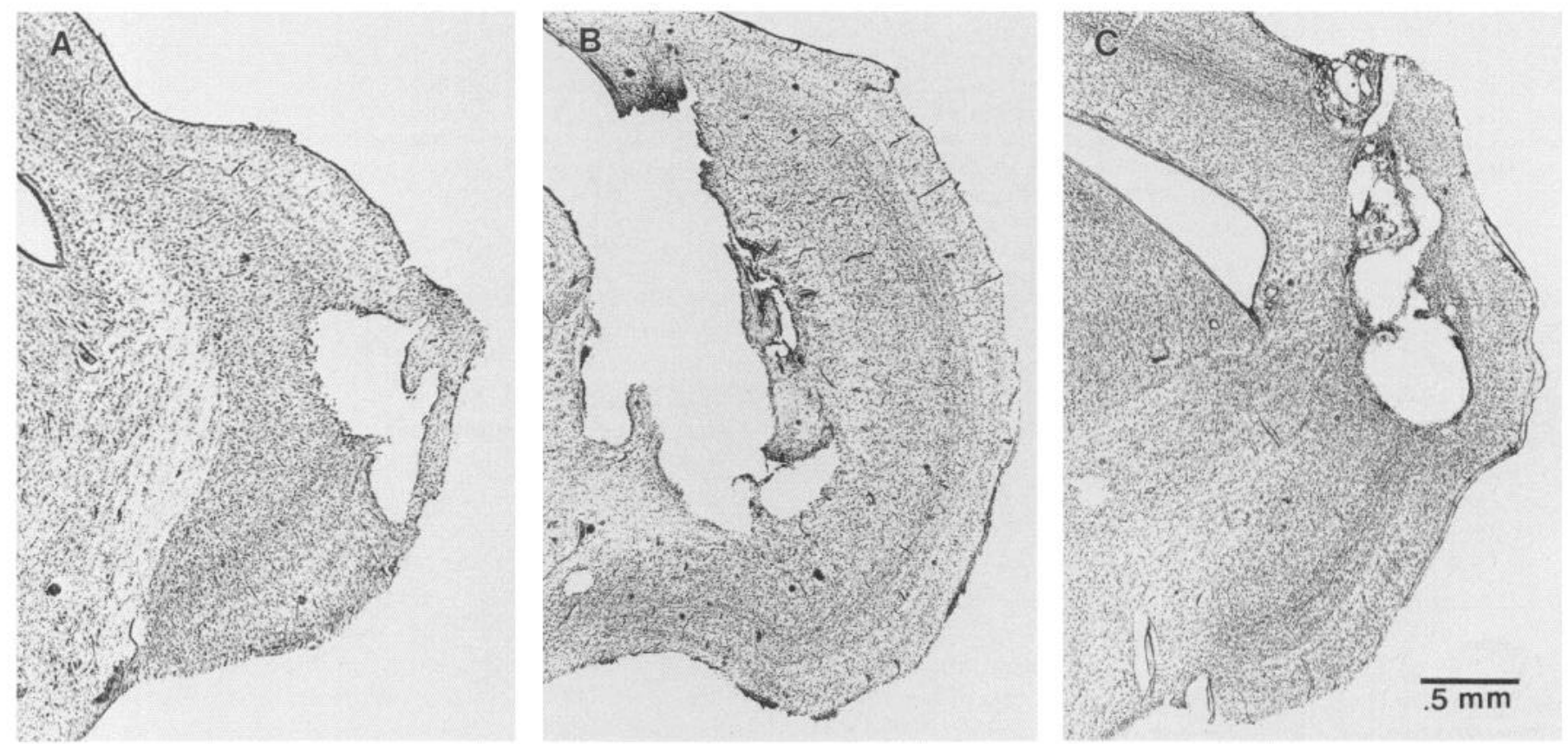

Figure 2. Muscimol injection sites in the optic tectum. These are Nissl-stained, transverse sections through the sites of injection. Dorsal is up and lateral is to the right. $A$ is from owl $2, B$ is from owl 3 , and $C$ is from owl 5 . Scale bar, $0.5 \mathrm{~mm}$. 
A

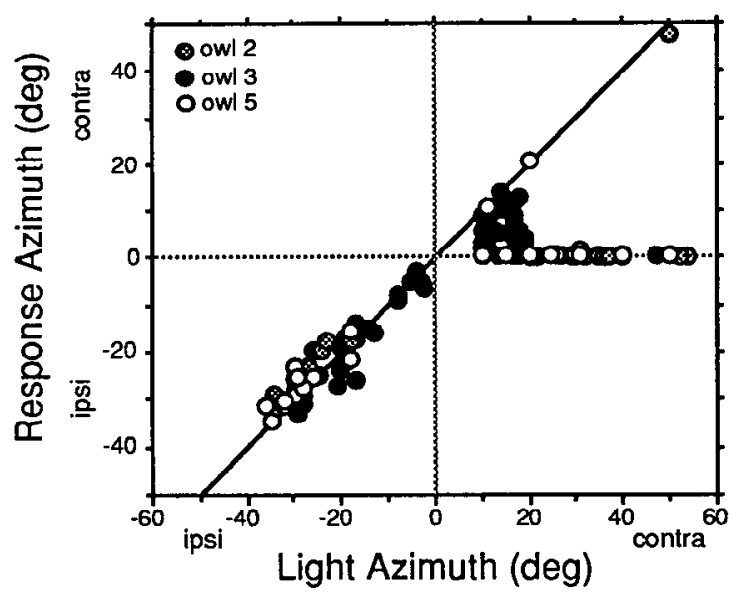

B

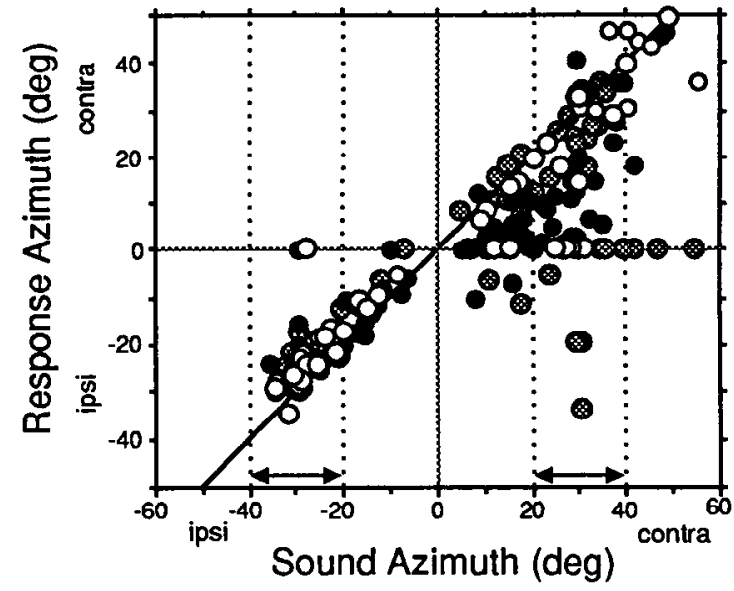

C

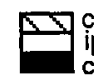
control. psi to injection contra to injection

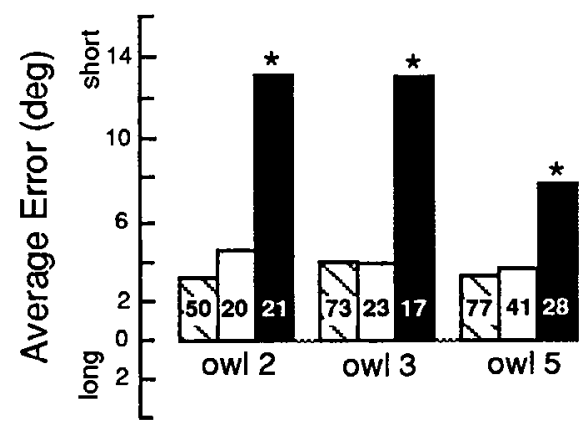

D

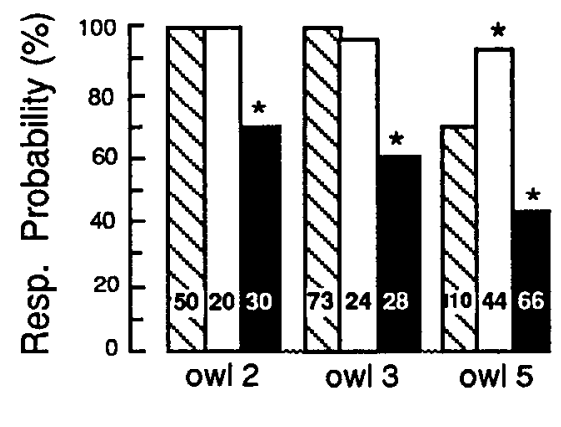

E

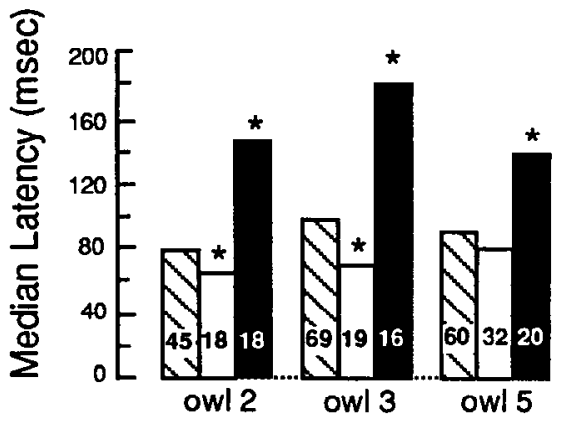

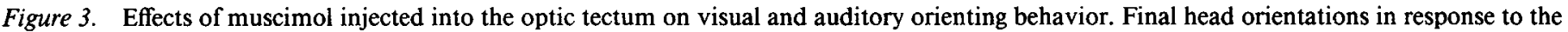

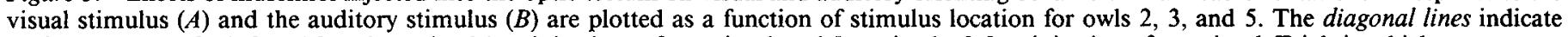

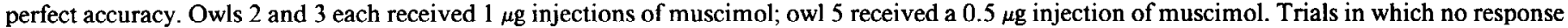

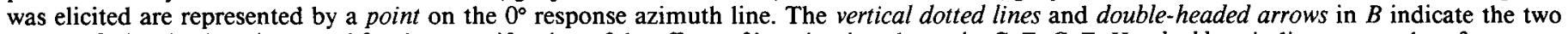

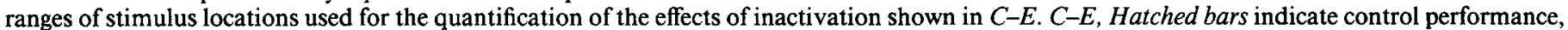

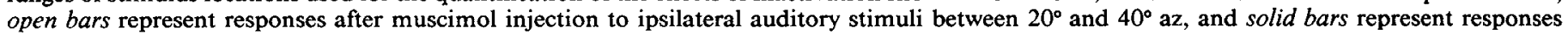

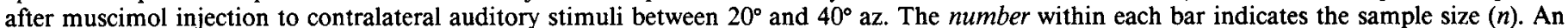

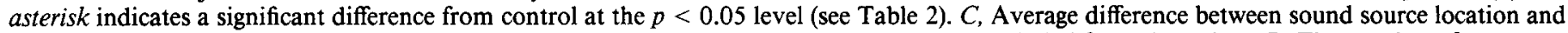

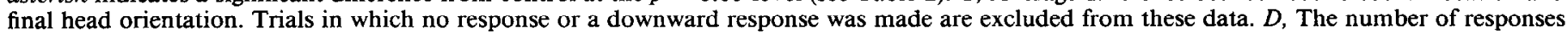

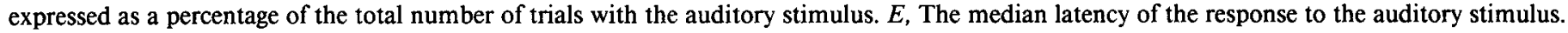

Methods). After a muscimol injection, none of the owls ever responded to a light stimulus located between $20^{\circ}$ and $50^{\circ}$ contralateral azimuth (Fig. $3 \mathrm{~A}$ ). Occasional responses were made by owl 2 to lights beyond $50^{\circ}$ az and by owl 5 beyond $65^{\circ}$ az (data not shown). Thus for these two birds, the extreme caudal tectum may not have been completely inactivated. Occasional responses were made by owls 3 and 5 to lights presented at azimuths of less than $20^{\circ}$ contralateral (owl 2 was not tested with lights in this region). The responses of owl 3 , which was tested most extensively in this frontal region, were inaccurate and unreliable, most being well short of the target. Because the responses to lights at frontal contralateral locations were abnormal, it is likely that the rostral end of the lectum was indeed inactivated by the muscimol and that these responses were mediated either by the opposite optic tectum or by the forebrain. However, we cannot exclude the possibility that the rostral tec- tum was only partially affected. Based on these data, and on the reconstructed injection sites (Fig. 2), we conclude that the muscimol injections inactivated at least the central portion of the tectum in each of the birds.

Responses to auditory stimuli located in the contralateral hemifield were often abnormal. In some trials, the animals failed to move at all (indicated as $0^{\circ}$ azimuth in Fig. $3 B$ ). In other trials, owls 2 and 3 turned toward the wrong side (Fig. $3 B$ ). In six trials, owl 3 turned the head straight down toward the feeder (these were treated as "no response" in the calculation of response probability). Of those trials in which the response was made in the correct direction, most responses stopped well short of the target. However, the magnitude of these responses tended to increase with sound source azimuth, they were rarely hypermetric, and in many cases they were perfectly accurate (Fig. $3 B$ ).

Quantitative analysis of the effects of muscimol injection (Ta- 


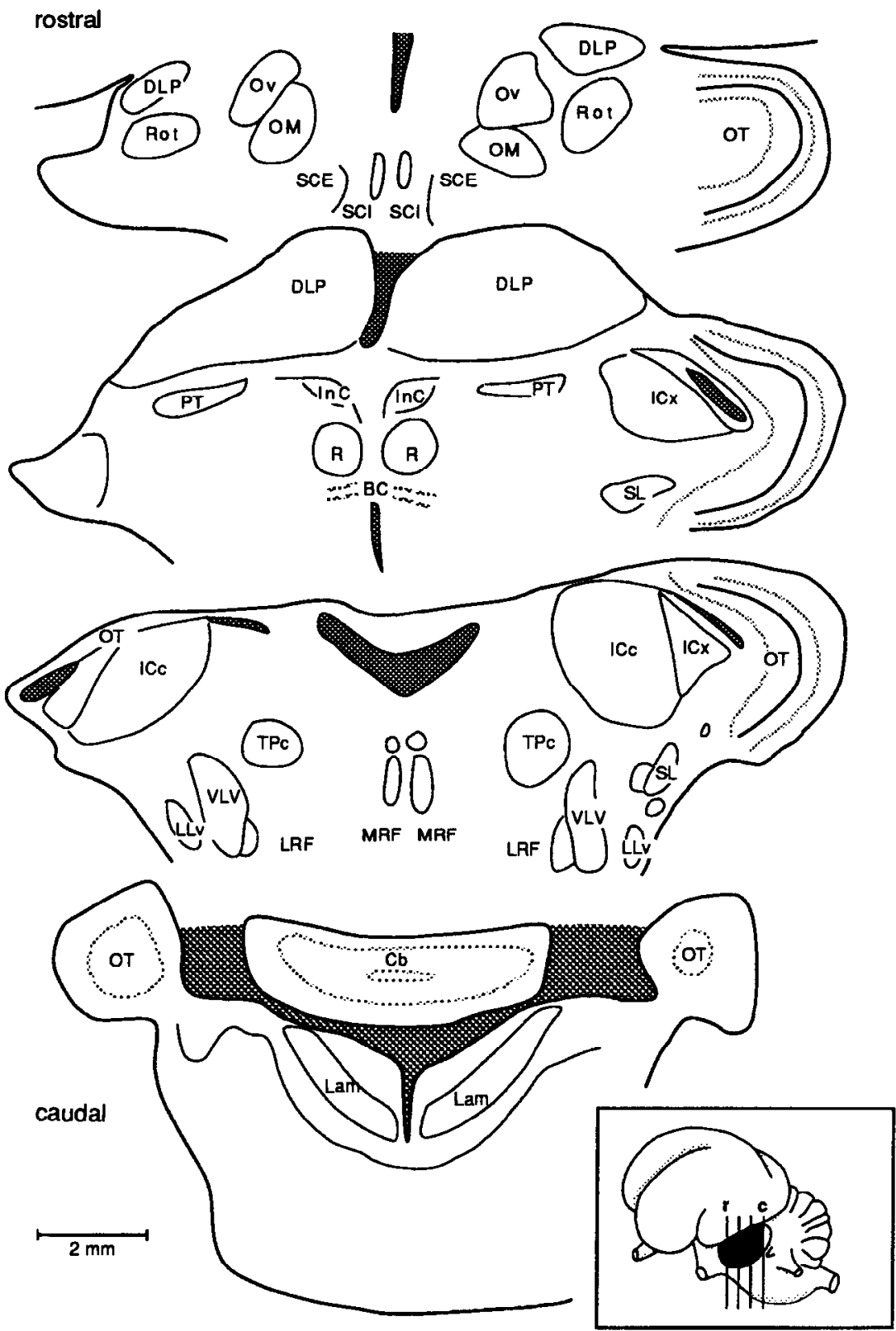

Figure 4. Reconstruction of the unilateral ablation of the optic tectum in owl 1. These are camera lucida drawings of Nissl-stained, transverse sections. The interval between sections is $2 \mathrm{~mm}$. The levels of the sections and the portion of the tectum that was lesioned are indicated in the inset $(r$, rostral; $c$, caudal). $C b$, cerebellum; $D L P$, posterior dorsolateral thalamic nucleus; $I C c$, inferior colliculus central nucleus; $I C x$, inferior colliculus external nucleus; $\ln C$, interstitial nucleus of $\mathrm{Ca}$ jal; $L a m$, nucleus laminaris; $L L v$, nucleus of the lateral lemniscus, ventral; $L R F$, lateral reticular formation; $M R F$, medial reticular formation; $O M$, occipitomesencephalic tract; $O T$, optic tectum; $O v$, nucleus ovoidalis; $P T$, pretectal nucleus; $R$, red nucleus; $R o t$, nucleus rotundus; $S C E$, stratum cellular externum; $S C I$, stratum cellular internum; $S L$, nucleus semilunaris; $T P C$, nucleus tegmenti pedunculo-pontinus, pars compacta; $V L V$, ventral nucleus of the lateral lemniscus. Scale bar, $2 \mathrm{~mm}$.

ble 2) was based on responses made to sound stimuli located between $20^{\circ}$ and $40^{\circ}$ either contralateral (represented in the portion of the tectum immediately surrounding the injection site) or ipsilateral relative to the side of the injection (dotted lines in Fig. $3 B$ ), both with and without the tectum inactivated. With the tectum inactivated, when auditory test stimuli were located on the contralateral side, the probability of response decreased markedly for each owl, the mean and SD of oricntation errors increased, and the median latency of response increased (Fig. $3 C-E$ ). Nevertheless, when the owls responded the magnitude of the response correlated $(p<0.001)$ with the location of the auditory stimulus (Fig. $3 B$ ). When auditory stimuli were located on the ipsilateral side, responses were normal, with the following exceptions: (1) the probability of response for owl 5 increased from a control value of $70 \%$ to $93 \%$ (those of owls 2 and 3 remained near $100 \%$ ), and (2) the median latency of response decreased for owls 2 and 3 (Fig. $3 E$ ).

The only aspect of the response that was not obviously affected by the muscimol injection was the speed of movement for contralateral and ipsilateral movements of equivalent size (data not shown): although for each owl muscimol in the tectum caused average speed to be slower for contralateral movements and faster for ipsilateral movements, in no case was the difference significant at the $p<0.05$ level (ANOVA).

\section{Performance after lesion of the optic tectum}

Despite tectal inactivation with muscimol, owls retained the capacity to orient toward contralateral sound sources. To determine whether this residual localization capacity was due to unaffected portions of the tectum, the tectum on the left side in owl 1 was lesioned (see Materials and Methods).

Histological reconstruction revealed that only a small piece of the caudal pole of the tectum (caudal 10\%) remained intact. The rest of the tectum had degenerated into a thin ribbon of tissue (Figs. 4, 5). Other structures damaged by the lesion included all of nucleus isthmi and nucleus semilunaris. In the IC, 

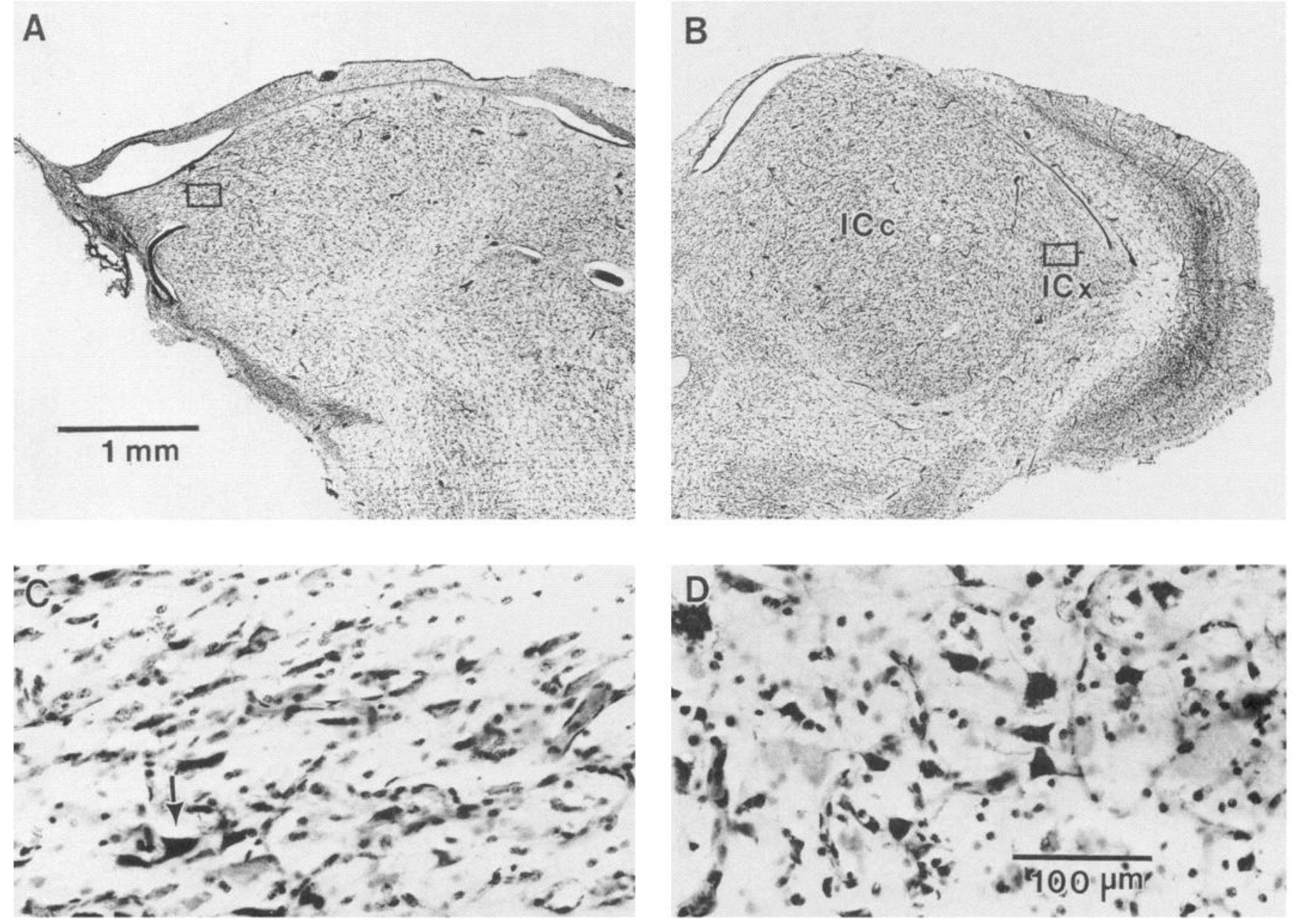

Figure 5. Transverse sections through the inferior colliculus of owl 1 showing degeneration of the $I C x$ on the side of the tectal ablation: Nisslstained sections from the lesioned side $(A$ and $C)$ and the unlesioned side $(B$ and $D)$. The high-magnification photographs $(C$ and $D)$ were taken at the locations indicated by the boxes in $A$ and $B$. One of the few neuronal somata that could be found in the region that normally corresponds to the ICx is indicated by the arrow in $C$. In the normal ICx $(D)$, this region contains numerous multipolar somata. The stained blood vessels are due to the fact that the brain was fixed by immersion postmortem. $I C c$, inferior colliculus central nucleus; $I C x$, inferior colliculus external nucleus. Scale bars: $A$ and $B, 1 \mathrm{~mm} ; C$ and $D, 0.1 \mathrm{~mm}$.

the ICx and ICs had degenerated as a direct or indirect result of the tectal lesions: the region beneath the tectal ventricle, normally occupied by relatively densely packed multipolar neurons of the ICx (Fig. 5D), had become a zone of sparse, abnormally shaped neurons (Fig. 5C). The ICc, on the other hand, appeared normal.

Owl 1 was tested on four separate days beginning 2 weeks and ending 12 weeks after the lesion was made. Because there were no significant differences $(p<0.05)$ between the data collected over this period, the data were combined from all postlesion test sessions. Most of the abnormal characteristics of auditory orienting behavior that were observed immediately following tectal inactivation in the other birds were evident in the behavior of owl 1 (Fig. 6). There was a conspicuous tendency to undershoot the target (Fig. 6B). However, responses increased systematically with sound source azimuth. Response latency was significantly longer to contralateral stimuli than to ipsilateral stimuli, but neither was significantly different from control performance (Table 2, Fig. $6 E$ ). The most notable difference from the previous birds was that this owl responded on every trial to contralateral auditory stimuli (Fig. $6 D$ ) and responses were never made in the wrong direction (Fig. $6 B$ ).

Unlike the muscimol-injected owls, the lesioned owl responded to contralateral visual stimuli. The owl would frequently turn its head toward visual stimuli located beyond $20^{\circ}$ contralateral, but the size of the head saccade was never more than about $20^{\circ}$ (Fig. 6A). When the target light was left on, the owl would make multiple, small saccades toward the target (Fig. 7); the owl exhibited the same behavior when orienting to the zeroing light. Thus, the owl responded to the visual stimulus in the contralateral hemifield but did not make large contraversive saccades to the stimulus. It did, however, make large contraversive saccades to the auditory stimulus (Figs. $6 B, 7$ ).

\section{Performance after inactivation of nucleus ovoidalis with muscimol}

Muscimol was injected into nucleus ovoidalis in owls 3 and 5 (Table 1). The histology indicated that, in owl 3 (Fig. 8A), most of the injections were made just dorsal to the center of the nucleus. However, a faint tract of gliosis indicated that at least 
A

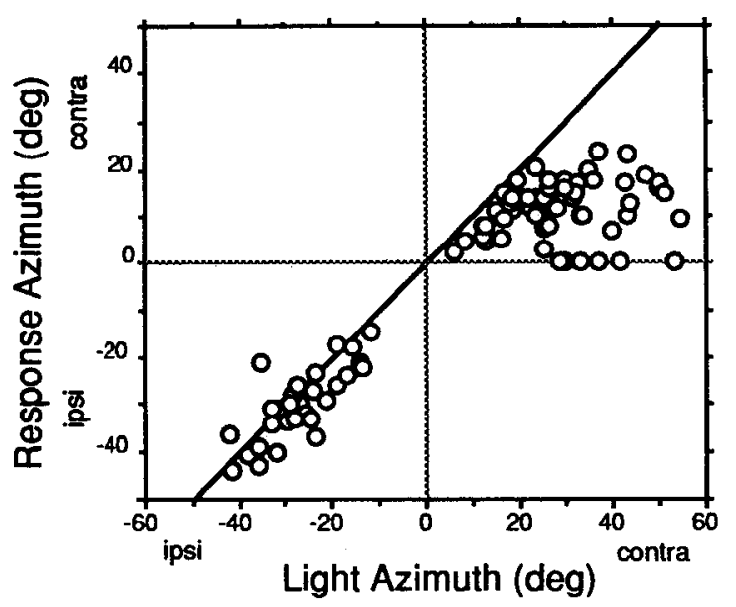

C
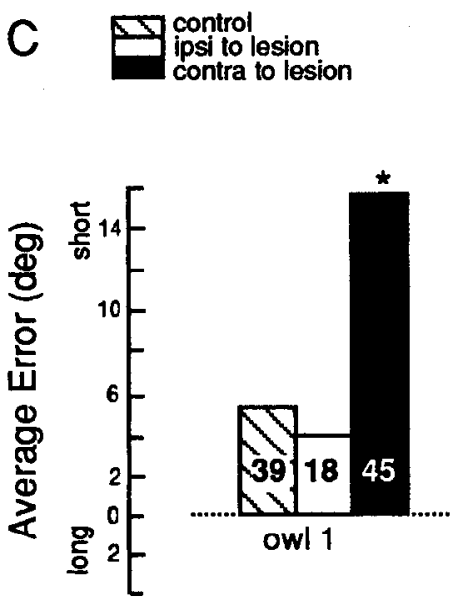

B

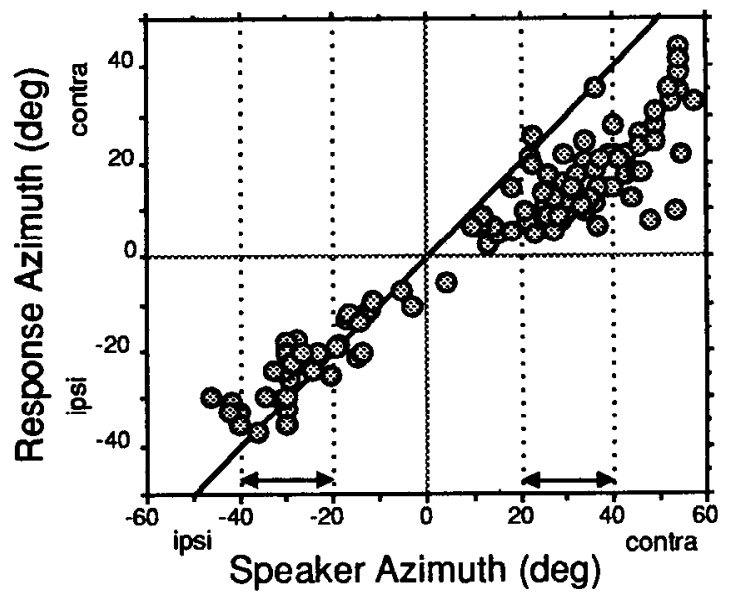

E

Figure 6. Long-term effects of a unilateral lesion of the optic tectum on visual and auditory orienting behavior. The data were gathered from owl 1 between 2 and 12 weeks postlesion. The formats of these graphs are the same as those in Figure 3. $A$, Visual orienting responses: head orientation after the first saccadic movement is plotted against visual stimulus location. $B$. Auditory orienting responses. The vertical dotted lines indicate the ranges of stimulus locations used for the quantification of auditory orienting responses $(C-E)$.

one of the four injections was centered about $1 \mathrm{~mm}$ below the nucleus. We do not know which injection this was. It is likely, though, that the muscimol spread up the path of the injector tube and affected nucleus ovoidalis nonetheless. In owl 5 (Fig. $8 B$ ), all of the injections were made in or on the border of nucleus ovoidalis, at approximately the center of its rostrocaudal extent.

The extent of the inactivated region was not assessed directly. However, injections containing 0.5 or $1.0 \mu \mathrm{g}$ of muscimol resulted in abnormal head posture: a chronic turn of the head toward the contralateral side (opposite to the direction of turn following tectal injections) and a roll of the head, about the line of sight, toward the contralateral side. No quantitative data were gathered from these experiments. Injections that contained 0.25 $\mu \mathrm{g}$ (standard dosage) of muscimol did not affect head posture in owl 5 and induced only a slight ipsiversive head drift in owl 3. Since most injection sites were centered in nucleus ovoidalis, we assume that at least this area, and perhaps more, was affected.

The effects of ovoidalis inactivation on auditory orienting behavior were quantified based on responses to test stimuli located between $20^{\circ}$ and $40^{\circ}$ az (same as for tectal inactivation; Table 2). The effects were different in the two birds (Fig. 9). Owl 5 was the most thoroughly tested and all of the injections appeared to have been centered in the nucleus. In this bird, response error increased for auditory stimuli located on the contralateral side, while the probability of response decreased for stimuli located on the ipsilateral side.

The sample size was small for owl 3. (This was the first owl to receive nucleus ovoidalis injections and, because the effects were so slight, we originally thought that the guide tube had been positioned incorrectly.) Keeping this in mind, orientation error decreased significantly (accuracy improved) for contralateral stimuli (Fig. 9C), due to the loss of the normal undershoot (Fig. $9 B$ ); the probability of response was $100 \%$ (same as control) to test stimuli presented on either side (Fig. 9D), and the latency of response was shorter than control latencies for ipsilateral stimuli (Fig. 9E). 


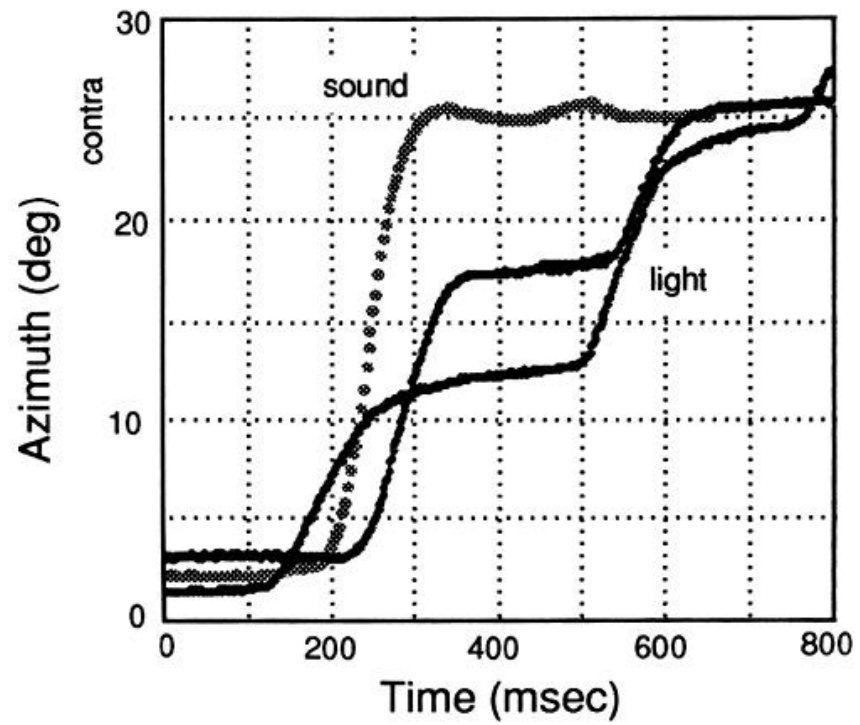

Figure 7 . Orienting responses to contralateral stimuli made 2 weeks after unilateral lesion of the optic tectum in owl 1. The graph plots head orientation as a function of time after stimulus onset for three trials in which the stimulus was located at $30^{\circ}$ contralateral azimuth. The broken trace is a response to the auditory stimulus; the solid traces are responses to the visual stimulus. In the trials with the visual stimulus, the light was left on until the head stopped moving.

\section{Performance after lesion of nucleus ovoidalis}

Nucleus ovoidalis was lesioned on the left side in owl 4 (Fig. $8 C$ ). Histological reconstruction indicated that the caudal and medial $50 \%$ of the nucleus remained intact. The rest of the nucleus was destroyed. No damage was apparent in the surrounding nuclei.

When tested two weeks after the lesion was made, owl 4 exhibited behavior similar to that described above for owl 3 (Fig. 9): response probability was $100 \%$ regardless of test stimulus location and the tendency to undershoot contralateral auditory targets was gone (Fig. 9B,C). A difference, however, was that the latency of response was longer, rather than shorter, to auditory stimuli on the ipsilateral side.

\section{Performance after inactivation of both optic tectum and} nucleus ovoidalis

Combined tectal and ovoidalis inactivation was carried out in three owls (Table 1). Because of contralateral visual neglect, the owls were zeroed using the auditory zeroing stimulus. Owl 3, which had nucleus ovoidalis inactivated with $0.25 \mu \mathrm{g}$ of muscimol and the optic tectum inactivated with $1.0 \mu \mathrm{g}$ of muscimol, responded to every auditory test stimulus located on the ipsilateral side with an accurate, short latency movement (Fig. 10). In contrast, out of 19 trials with the auditory test stimulus located between $20^{\circ}$ and $40^{\circ}$ contralateral, the owl turned in the direction of the stimulus only twice, both responses stopping short of the target (Fig. 10B). In addition, the owl never responded to contralateral auditory test stimuli located more frontally, between $5^{\circ}$ and $20^{\circ}$ az $(n=7)$.

Owl 5 also had nucleus ovoidalis and the optic tectum inactivated with muscimol, but the quantity of muscimol injected into the tectum was less, only $0.5 \mu \mathrm{g}$ (Table 1$)$. In response to ipsilateral auditory stimuli located between $20^{\circ}$ and $40^{\circ}$ az, this bird oriented reliably $(92 \%$ response probability, up from the $70 \%$ control value), accurately, and with a short latency (Fig. $10 C-E$ ). In contrast, in response to contralateral test stimuli located between $20^{\circ}$ and $40^{\circ} \mathrm{az}$, the owl turned in the direction of the source twice out of 31 trials, each response stopping well short of the target (Fig. $10 B, D$ ). This owl also never responded $(n=5)$ to contralateral test stimuli located more frontally, between $10^{\circ}$ and $20^{\circ} \mathrm{az}$. Instead, the owl remained in the zero position. Response probability increased (four of five trials) for contralateral test stimuli located beyond $45^{\circ}$ az, although the responses always stopped short of the target (this would be consistent with the smaller injection having caused incomplete inactivation of the caudal optic tectum; see Performance after tectal inactivation with muscimol, above).

In owl 4 , the rostral $50 \%$ of nucleus ovoidalis was lesioned (Fig. $8 C$ ) two weeks before testing and the optic tectum was injected with $1.0 \mu \mathrm{g}$ of muscimol. As was the case for owls 3 and 5, owl 4 responded reliably, accurately, and with a short latency to ipsilateral test stimuli, but never responded with a normal orienting movement to contralateral test stimuli between $20^{\circ}$ and $40^{\circ}$ az (Fig. $10 C-E$ ). In a third of the contralateral
A

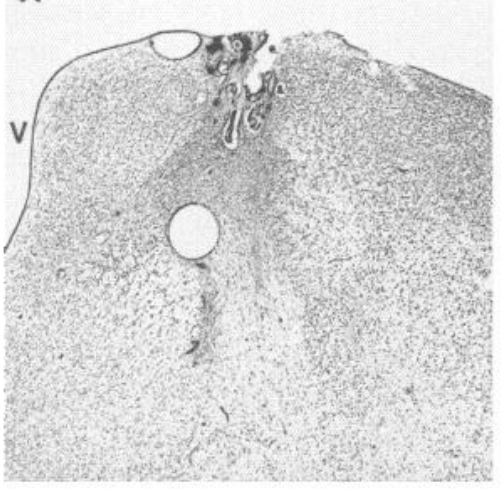

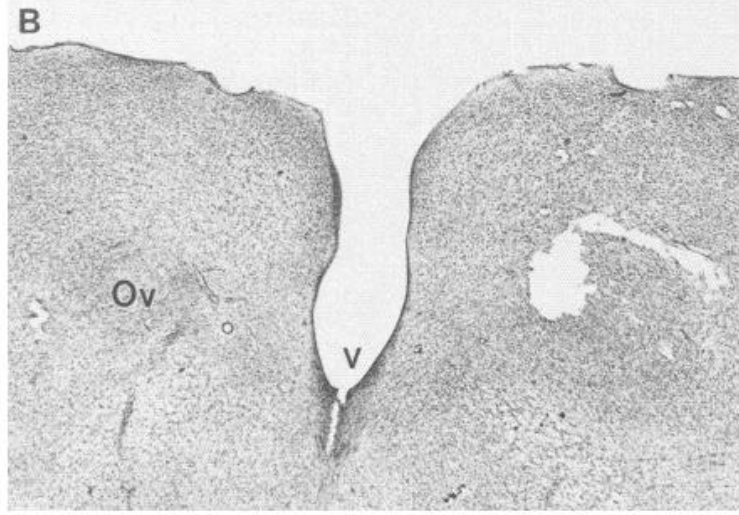

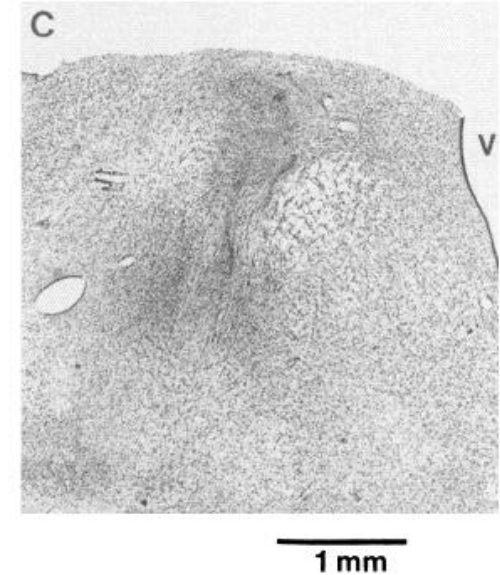

Figure 8. Muscimol injection sites and lesions in the nucleus ovoidalis. These are Nissl-stained, transverse sections through the sites of injection $(A$ and $B$ ) or lesion $(C)$. A, A section through the right nucleus ovoidalis of owl 3. Most of the injections appear to have been made within the nucleus, although gliosis from an injection just beneath the nucleus is evident. $B$, A section from owl 5 showing the normal nucleus ovoidalis $(O v)$ on the left side and the injected nucleus on the right. $C$. The left nucleus ovoidalis in owl 4 in which the rostral $50 \%$ of the nucleus was destroyed on the left side. Dorsal is up. $V$, midline ventricle. Scale bar, $1 \mathrm{~mm}$. 
A

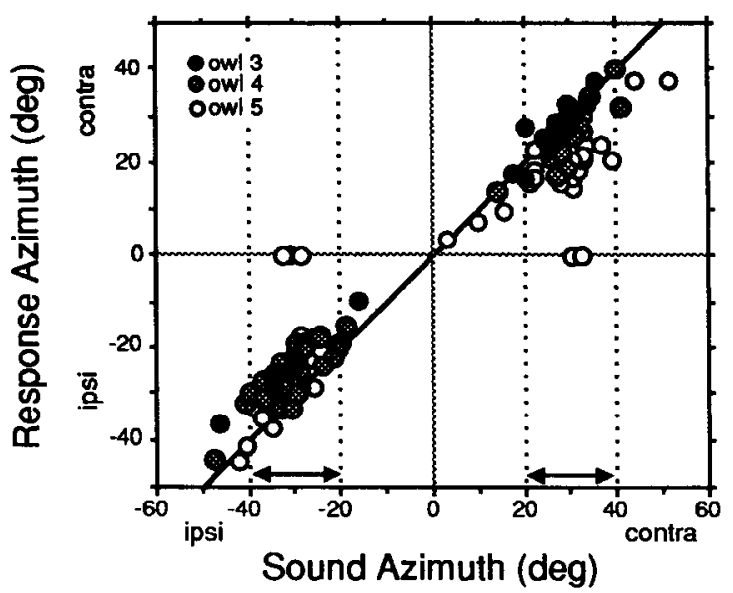

C
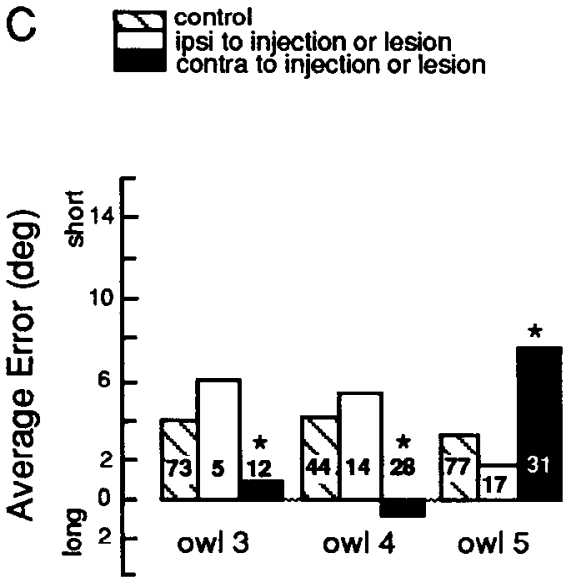

D

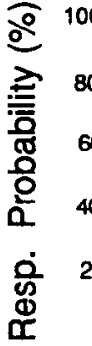

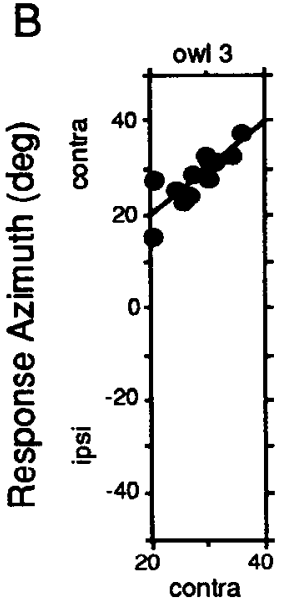
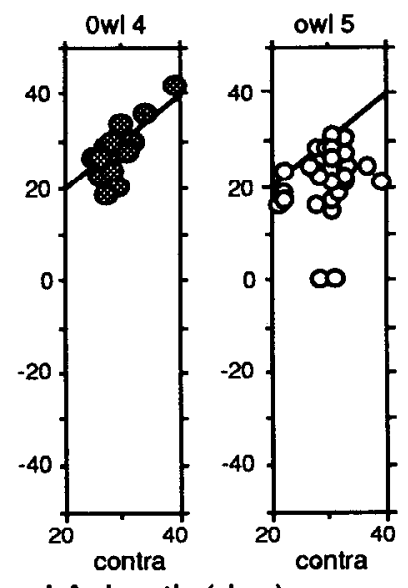

Sound Azimuth (deg)

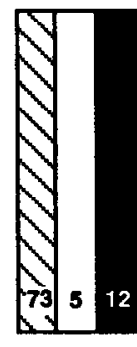

owl 3

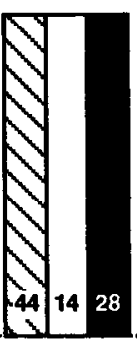

owl 4

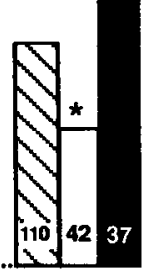

owl 5
E

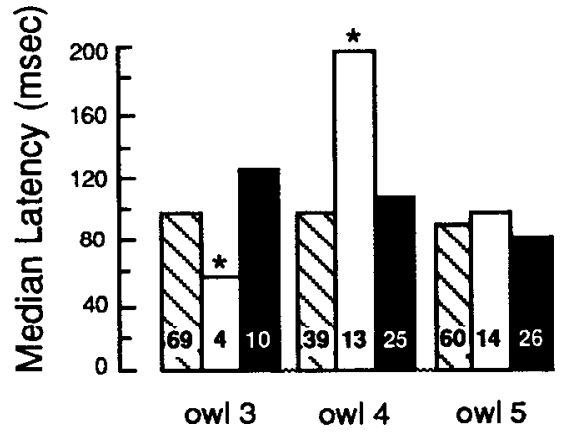

Figure 9. Effects of muscimol injected into nucleus ovoidalis (owls 3 and 5) or of lesioning nucleus ovoidalis (owl 4) on auditory oricnting responses. The data are plotted in the same format as described for Figure 3 . $A$, Final head position is plotted against auditory stimulus location. $B$, The data from each bird for contralateral stimulus locations between $20^{\circ}$ and $40^{\circ}$ az are shown separately because they overlap in $A$. $C-E$, Quantification of auditory orienting responses to stimulus locations between $20^{\circ}$ and $40^{\circ}$ az.

trials, this owl responded with a downward movement toward the feeder; data from these trials were included in the calculation of response probability as a "no response" and were excluded from the calculations of response error and latency. In the remaining trials, no response at all was made. For contralateral auditory stimuli located beyond $40^{\circ}$ az, the probability of response increased, as it did for visual stimuli located beyond $50^{\circ}$ az (data not shown), suggesting that the caudal tectum had not been inactivated by the muscimol injection.

To maximize the likelihood of eliciting orienting responses to contralateral test stimuli, each of these three birds was presented on a number of trials with the test stimulus alone (without a preceding zeroing stimulus). These trials were run when the owls assumed the zero position without the zeroing stimulus having been activated. The test stimulus was always located near $30^{\circ}$ contralateral. Orienting responses were never elicited on these trials.

The behavior of all three owls indicated that they could hear sounds originating from the contralateral hemifield. Each re- sponded reliably by zeroing the head in response to the auditory zeroing stimulus (which sounded different from the test stimulus due to differences in the frequency response and mounting of the loudspeakers), even when the head was oriented so that the zeroing speaker was located contralaterally. In addition, owl 4 often made downward responses (described above) immediately after test stimulus onset, when the test stimulus was located in the affected zone (out to about $40^{\circ}$ contralateral azimuth).

\section{Discussion}

The results demonstrate that two distinct pathways in the midbrain and forebrain can mediate auditory orienting behavior in the owl. After the optic tectum is inactivated unilaterally, owls continue to orient to contralateral auditory stimuli (Fig. 3). They lose this capacity when the primary auditory nucleus of the thalamus, nucleus ovoidalis, is also inactivated (Fig. 10). Thus, auditory spatial information represented in the forebrain can support orienting behavior when the tectum is inactive. Conversely, after nucleus ovoidalis is inactivated or lesioned uni- 
A

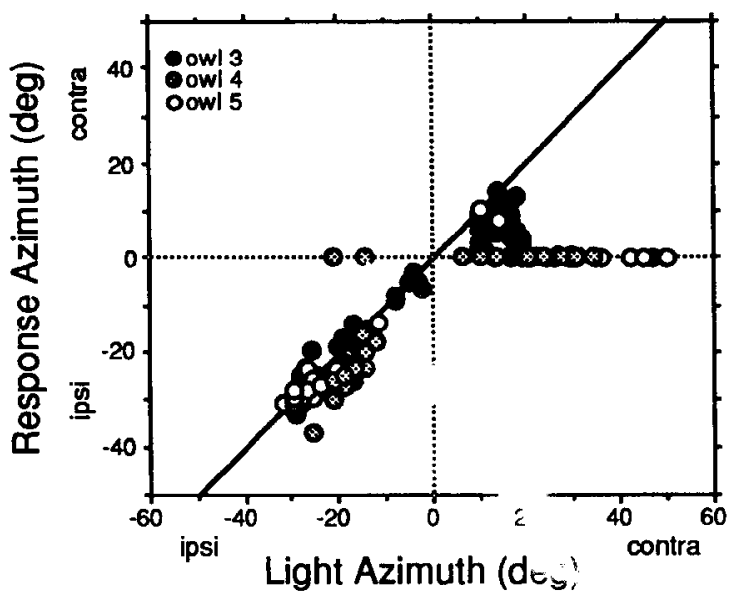

B

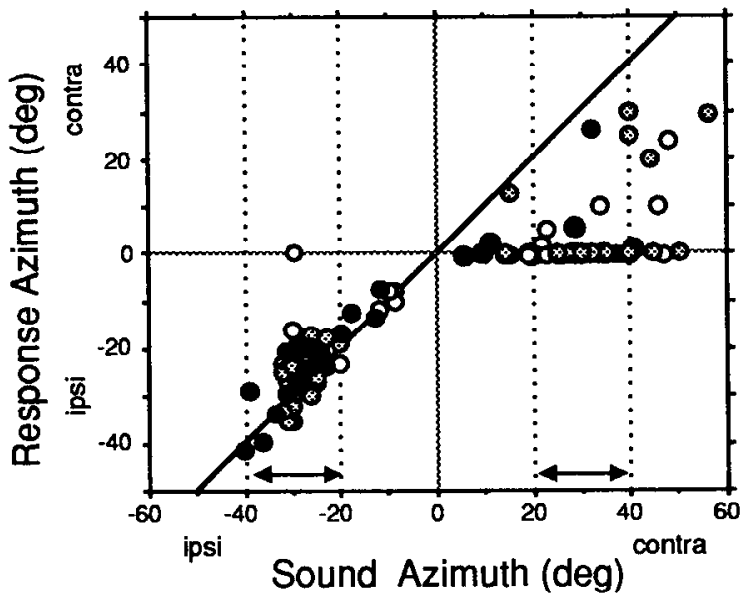

C
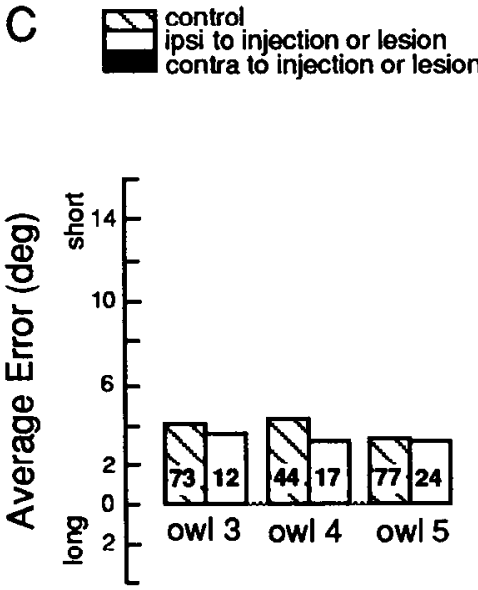

D

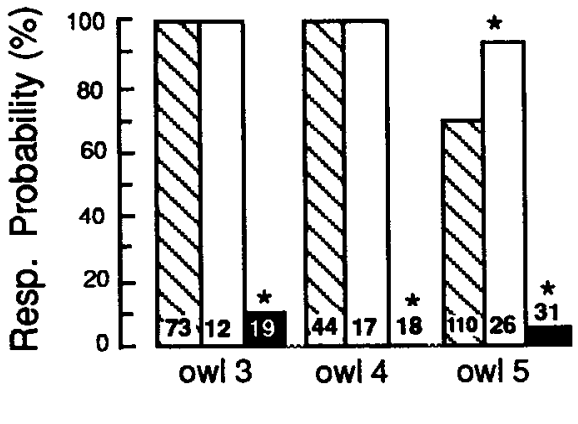

$E$

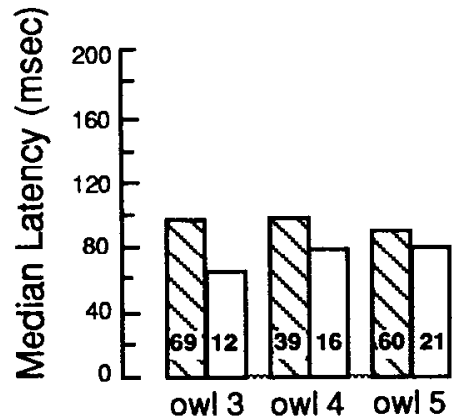

Figure 10. Effects of inactivating both the optic tectum and nucleus ovoidalis on visual and auditory orienting responses. The data are plotted in the same format as described for Figure 3. Owl 3 received a $1.0 \mu \mathrm{g}$ injection of muscimol in the tectum and a $0.25 \mu \mathrm{g}$ injection of muscimol in the nucleus ovoidalis on the same side. Owl 4 received a $1.0 \mu \mathrm{g}$ injection of muscimol in the tectum and had large, electrolytic lesions in the ipsilateral nucleus ovoidalis. Owl 5 received a $0.5 \mu \mathrm{g}$ injection of muscimol in the teclum and a $0.25 \mu \mathrm{g}$ injection of muscimol in the ipsilateral nucleus ovoidalis. For $C$ and $D$, average error and median latency were not calculated for contralateral stimuli, because of the lack of response.

laterally, owls continue to orient to contralateral auditory stimuli (Fig. 9), and lose this capacity when the ipsilateral optic tectum is also inactivated (Fig. 10), indicating that information represented in the tectum is essential to auditory orienting behavior when the nucleus ovoidalis is inactive. Together, the data demonstrate that both sound localization and the control of gaze can be carried out by pathways either through the midbrain or the forebrain.

The relative importance of these two brain regions to sound localization almost certainly varies depending on behavioral context. The optic tectum mediates rapid redirections of gaze and, in lower vertebrates, ballistic attack movements that lead directly to prey acquisition (Ingle and Sprague, 1975; Stein, 1988). Auditory units in the tectum, though spatially tuned, are not highly specialized for different types of sound: nearly all respond best to broad-band noise stimuli (King and Palmer, 1983; Knudsen, 1984b; Hirsch et al., 1985). Therefore, shortlatency neural responses in the optic tectum provide a nonselective representation of sound source locations.
The forebrain may be essential for the elaboration of more complex behaviors (see below) and may be critical for the selection of stimuli to which attention should be directed. Forebrain auditory units can be highly differentiated with respect to their stimulus requirements (Brugge et al., 1969; Suga, 1990; Sutter and Schreiner, 1991), and the forebrain has been shown to be involved in the identification and discrimination of complex auditory stimuli (Neff et al., 1975; Heffner and Heffner, 1984; Petersen et al., 1988; Phillips and Farmer, 1990; Riquimaroux et al., 1991; Zatorre et al., 1992). It is possible that the effects of inactivating just the auditory thalamus in the owl would have been severe, if the behavioral paradigm had required sound identification or a more complicated response such as locomoting to the source. With regard to sound localization, additional processing that probably occurs in the forebrain includes the comparison of the frequency spectrum of a familiar sound with the remembered spectrum of that sound, and the interpretation of the sound's spectrum in the context of stored information about the (familiar) physical acoustical environ- 


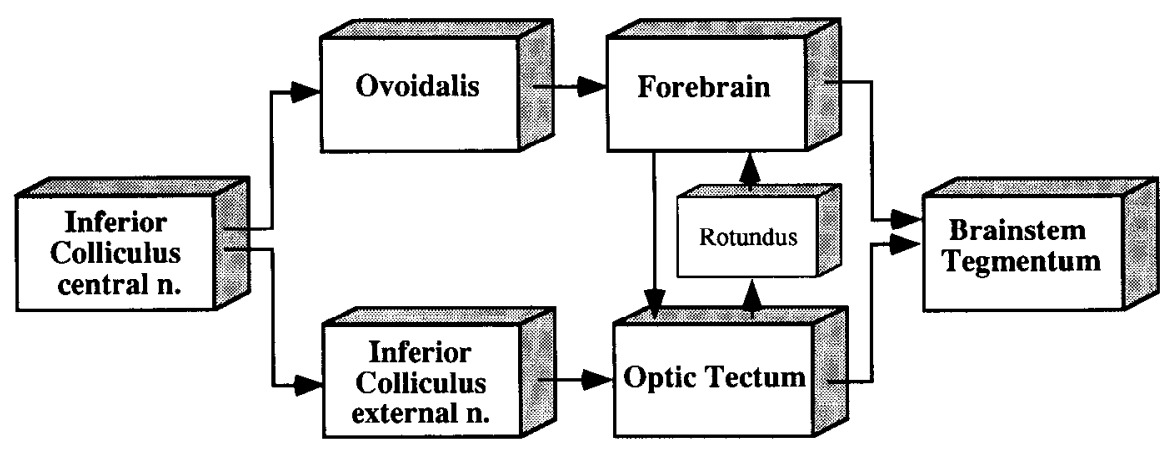

Figure 11. Parallel pathways for auditory orienting behavior suggested by the results of this study. Auditory spatial analysis is carried out in parallel in the colliculo-forebrain and colliculo-tectal pathways. Forebrain and tectal information is integrated and coordinated by strong interconnections (Powell and Cowan, 1961; Mcllwain, 1973; Balaban and Ulinski, 1981). Both the forebrain and the tectum transmit motor control signals to movement gencrating circuitry in the brainstem tegmentum (Leichnetz et al., 1981; Huerta and Harting, 1982). Additional connections between the ICx and forebrain (Huffman and Henson, 1990) could be included, but the data indicate they are not essential to the behavioral assay used in this study.

ment. Both processes involve memory retrieval and both contribute to sound localization (Gardner, 1969; Blauert, 1983). The resulting information might be available only to the forebrain representation of space, or it might be sent back to the midbrain to improve the short-latency spatial information that is derived solely from interaural differences and ear directionality cues.

Our hypothesis is that auditory orienting behavior in owls, like visual orienting behavior in primates (Schiller et al., 1980), is mediated in parallel by midbrain and forebrain pathways (Fig. 11). When a stimulus is novel or threatening, tectal circuits alone can redirect the animal's gaze immediately toward the source (Grobstein et al., 1983; Stein, 1988). Normally, however, forebrain processes contribute additional spatial information and select from among stimuli those that are worthy of attention. The result of this processing is transmitted directly, as well as via the optic tectum, to movement generating circuitry in the brainstem tegmentum (Leichnetz et al., 1981). The command to redirect gaze consists, therefore, of signals from the forebrain and optic tectum, the relative strengths of which vary with behavioral context.

\section{Attentional and audiomotor deficits with tectal inactivation}

Inactivation of the optic tectum alone causes immediate changes in auditory orienting behavior (Fig. 3): (1) the probability of response to sounds originating from the contralateral side decreases; (2) when a response is made, it is usually (but not always) short of the target and sometimes is in the wrong direction; and (3) the latency of response is longer to contralateral stimuli and shorter to ipsilateral stimuli. These effects are not due to fundamental sensory or motor deficits: the animals respond to, and therefore can hear, sounds from contralateral sources and in most instances they localize them correctly to the contralateral side; in addition, the animals are capable of making contraversive head saccades of all sizes in response to zeroing and test stimuli.

Instead, most of the effects could be accounted for in terms of a deficit in the control of attention. The optic tectum is known to be involved in orienting attention, and the tecta on opposite sides compete for control of attentional mechanisms (Wurtz and Goldberg, 1972; Rafal et al., 1988; Desimone et al., 1990; Posner and Petersen, 1990; Sprague, 1991). These studies indicate that a disruption in attentional control could account for many of the effects of unilateral tectal inactivation, including (1) the frequent, spontaneous, ipsiversive saccades and the paucity of contraversive saccades; (2) the accurate responses to stimuli on some trials, but no response at all on others; and (3) the short response latencies to ipsilateral stimuli and the long response latencies to contralateral stimuli.

Another, nonexclusive explanation for some of the effects of tectal inactivation is a deficit in sensory or motor space processing. The increased tendency to undershoot auditory targets, which has been observed previously in owls with lesions of the ICx (Wagner, 1993), could represent a disruption in auditory space processing that leads to an underestimation of stimulus location. Short responses could also reflect a deficit in motor space coding. Signals from the optic tectum may normally combine with similar signals from other structures to encode movement amplitude (Fig. 11). Absence of the tectal contribution under conditions that normally evoke a strong tectal output could result in an inadequate amplitude signal and hypometric movement. In primates, inactivation of the optic tectum causes hypometric eye saccades (Albano et al., 1982; Hikosaka and Wurtz, 1985), even though the tectum is thought to play a secondary role to the forebrain in visual localization in these species.

As is true of primates, the tendency of tectally lesioned owls to undershoot targets persists for months (Fig. 6; Schiller et al., 1987). It is interesting that owls and primates do not adjust for this hypometria, considering that they experience a large, consistent error signal and must make corrective movements following every saccade. This indicates that output from the optic tectum is somehow necessary for the adaptive regulation of the gain of gaze control signals.

\section{Auditory and visual localization without the tectum}

Auditory localization. Despite the possibility that tectal inactivation may induce a deficit in auditory space coding, owls can nevertheless localize sounds originating from the region of space normally represented by the inactivated portion of the tectum. This is indicated by the observation that, following muscimol injection into the tectum, in those trials in which responses were made, the responses correlated strongly with sound source azimuth and were rarely hypermetric (Fig. 3B). This conclusion is also supported by the data from owl 1 (Fig. 6), in which essentially the entire optic tectum had been lesioned on one side 
(Fig. 4). Not only did the owl tend to respond in the correct direction to contralateral stimuli, but the azimuth of the final head position increased systematically with stimulus azimuth. Thus, the nervous system can analyze, represent, and act upon auditory spatial information without access to the optic tectum.

It is conceivable that the auditory system extracts spatial information from frequency-specific cues at only one level, in the ICx, and that the ICX is essential, therefore, to sound localization. The ICx in mammals projects not only to the optic tectum, but also to the thalamus and from there to the forebrain (Huffman and Henson, 1990). If the ICx in owls also projects to the thalamus, this projection could convey to the forebrain the same auditory spatial information that is conveyed to the optic tectum. However, owls with electrolytic lesions of the ICx exhibit the same auditory localization behavior as that described here for owls with the tectum inactivated, including an ability to localize, but a tendency to undershoot, the target (Wagner, 1993). Moreover, owl 1 of this study localized contralateral sound sources despite the fact that the ICx was largely destroyed as a consequence of the tectal lesion (Fig. $5 C$ ). Also, the deep tectal injection site in owl 3 (Fig. $2 B$ ) almost certainly caused some inactivation of the $\mathrm{ICx}$ as well as of the tectum. These results suggest, therefore, that sound localization can be accomplished without the contribution of the auditory space processing that occurs in the $\mathrm{ICx}$.

The alternative is that spatial information is extracted from frequency-specific cues at other levels in the auditory pathway. This possibility is supported by a study on cats showing that lesions restricted to primary auditory cortex, which contains sharply frequency-tuned neurons, cause deficits in the ability to locomote to sound sources (Jenkins and Merzenich, 1984). The responses of neurons in these regions are dominated by input from the classical (tonotopic) auditory pathway and there is no anatomical or physiological evidence of input originating from the ICX (Huffman and Henson, 1990). Neurons in these regions are tuned for frequency-specific localization cues (Brugge et al., 1969; Imig and Adrian, 1977; Middlebrooks et al., 1980), as are neurons in the ICc. Thus, the ability of owls to orient to sound sources without the ICx, and the inability of cats to locomote to sound sources following lesions in the tonotopic auditory pathway above the level of the IC suggest that the auditory system derives spatial information from frequency-specific cues in parallel in the forcbrain and midbrain.

Visual localization. In contrast to the minor effect of tectal inactivation on auditory orienting behavior, its effect on visual orienting behavior is profound. No visual stimulus elicits a response, including high-contrast objects brought to within millimeters of the contralateral eye or bright flashes in a darkened room presented on the contralateral side beyond $20^{\circ}$ az. We interpret this as a fundamental visual deficit. It suggests that in owls, as in lower mammals and other nonmammalian vertebrates, the optic tectum normally plays a dominant role in visually guided behavior.

In owl 1 , visual neglect diminished with time, revealing an interesting difference between the access of visual versus auditory spatial information to the motor circuitry that subserves orienting movements in tectally lesioned animals. Within 3 weeks of receiving a virtually complete tectal lesion (Fig. 4), owl 1 began responding to contralateral visual test stimuli. However, unlike the large head saccades that were elicited by auditory stimuli, saccades elicited by visual stimuli were never greater than about $20^{\circ}$ and were often made in rapid succession (Fig.
7), similar to "staircase" eye saccades elicited in monkeys and cats by continuous tectal microstimulation (Robinson, 1972; McIlwain, 1986).

\section{Auditory orienting behavior with thalamic inactivation}

The pattern of effects that resulted from inactivating (or lesioning) the nucleus ovoidalis was not consistent across birds (Fig. 9). Response error to contralateral stimuli could increase or actually decrease (improved accuracy) relative to control performance. Response latency to ipsilateral stimuli could increase, decrease, or be unchanged. Response probability was unaffected in two owls, but decreased for ipsilateral stimuli in owl 5. Thus, although some aspect of auditory orienting behavior was affected significantly in each of the owls, the effects were, in general, minor and idiosyncratic. This variability might reflect the heterogeneity of the auditory information represented in nucleus ovoidalis (in contrast to the uniform, spatial information represented in the optic tectum) coupled with differences across animals in the portions of the nucleus that were inactivated (which were not assessed directly). Nevertheless, the disruption of auditory information processing that resulted when nucleus ovoidalis was inactivated (lesioned) alone was sufficient in every case to disable completely the auditory orienting responses to contralateral stimuli when it occurred in combination with tectal inactivation (compare Figs. 3, 10).

\section{Inability to orient toward sound sources following tectal and thalamic inactivation}

When the optic tectum and the nucleus ovoidalis were both inactivated, the owls either failed to respond to contralateral auditory test stimuli or responded with a downward turn toward the feeder. These owls were highly trained and their motivation was continuously monitored by interspersed trials with ipsilateral auditory test stimuli. Moreover, conditions were optimized for sound localization: the sound chamber was dark and quiet, and there were no competing stimuli to hold the animal's attention. Rare, contraversive movements to auditory test stimuli located in the affected region of space between $20^{\circ}$ and $40^{\circ}$ az were extremely hypometric (Fig. $10 \mathrm{~B}$ ), suggesting the possibility that they were mediated by a small population of broadly tuned neurons at the caudal end of the tectum that were not inactivated (Lee et al., 1988).

Because the owls still oriented their gaze forward in response to contralateral auditory zeroing stimuli, they could both hear contralateral sounds and make contraversive head saccades. As pointed out previously, this behavior did not require source localization since the owls were trained to zero the head on the body in response to this stimulus (the owls never oriented to the test stimulus when it was presented alone in the affected contralateral zone). The ability of the owls to respond to the zeroing sound when it originated contralaterally implies that unaffected components of the auditory pathway are capable of detecting and identifying contralateral sounds (the zeroing and test stimuli sounded different). The likely substrates for this residual capacity are the unaffected pathways on the opposite side of the brain.

The absence of an orienting response to contralateral auditory test stimuli was not due to an inability to pay attention to sounds originating from the contralateral side, since the owls responded quickly and appropriately (and, therefore, attended) to zeroing stimuli located contralaterally relative to the head. Another possibility is that ovoidalis inactivation caused a motor deficit that, 
combined with the tectal motor deficit, resulted in a complete modality-specific interruption of motor command signals. However, there was no indication of any motor deficit following inactivation of nucleus ovoidalis alone. Moreover, this explanation implies that the primary consequence of inactivating a sensory nucleus in the thalamus is a direction-specific motor deficit.

A simple explanation that is consistent with all of the results is the following. The optic tectum and the nucleus ovoidalis both derive auditory spatial information from the ICc (Fig. 11). The spatial information that is contained in the frequency-specific channels of the ICc is processed in parallel in the midbrain and forebrain. Each pathway is capable of determining the locations of sound sources in contralateral hemifield, and either pathway is capable of directing the animal's attention and gaze toward contralateral locations. Because tectal inactivation alone (Fig. 3) causes more severe deficits than does ovoidalis inactivation alone (Fig. 9), the optic tectum appears to play a more obligatory role in auditory orienting behavior, at least in the barn owl. Inactivating both pathways leaves the owl incapable either of localizing contralateral sound sources or of acting upon the auditory spatial information.

The literature on the neural substrate for sound localization contains many apparently contradictory conclusions with regard to the importance of the forebrain to sound localization (Neff et al., 1975). Jenkins and Masterton (1982) pointed out correctly that many of the results indicating little or no effect of unilateral forebrain lesions on sound localization can be explained by inadequate testing procedures: performance on two-choice tests in which sound sources were either to the left or to the right of the animal could have been based on the discrimination of localizable from nonlocalizable stimuli, rather than on the relative locations of two localized stimuli. More recent experiments that required discrimination among multiple potential locations in a single hemifield demonstrate clearly the importance of the forebrain to sound localization (Jenkins and Merzenich, 1984; Kavanagh and Kelly, 1987; Heffner and Heffner, 1990). This consideration cannot account, however, for the residual discrimination abilities of animals subjected to bilateral forebrain lesions (Ravizza and Masterton, 1972; Ravizza and Diamond, 1974; Heffner and Masterton, 1975; Kelly, 1980), nor does it explain the ability of humans subjected to unilateral hemispherectomy to localize contralateral sound sources (Neff et al., 1975). Differences in the severity of localization deficits following forebrain lesions may reflect differences across species in the importance of the forebrain to various aspects of sound localization, but they also reflect differences in the sensory discriminations and behavioral tasks required of the animals in the different studies. The data presented in this study suggest that the sound localization capacities that survive auditory forebrain lesions may depend on the function of the optic tectum, as is thought to be the case for the residual visual localization capacities that survive visual forebrain lesions in humans (Trevarthen, 1970; Cowey and Stoerig, 1991).

The capacity of the forebrain to mediate saccadic orienting movements has not been recognized previously in nonmammalian species. In primates the frontal eye fields of the forebrain can control eye saccades independently of the optic tectum (Schiller et al., 1980). When both the frontal eye fields and the optic tectum are inactivated, the ability to orient the eyes toward contralateral visual stimuli is lost. An analogous pattern of deficits in auditory orienting behavior is reported here for owls, demonstrating that in owls, as in primates, mechanisms for controlling saccadic changes in gaze reside in the forebrain as well as in the midbrain.

\section{References}

Aitkin LM, Webster WR, Veale JL, Crosby DC (1975) Inferior colliculus. I. Comparison of response properties of neurons in central, pericentral and external nuclei of adult cat. J Neurophysiol 38:11961207.

Aitkin LM, Gates GR, Phillips SC (1984) Responses of neurons in inferior colliculus to variations in sound-source azimuth. J Neurophysiol 52:1-17.

Albano JC, Mishkin M, Westbrook LE, Wurtz RH (1982) Visuomotor deficits following ablation of monkey superior colliculus. J Neurophysiol 48:338-351.

Balaban CD, Ulinski PS (1981) Organization of thalamic afferents to anterior dorsal ventricular ridge in turtles. I. Projections of thalamic nuclei. J Comp Neurol 200:95-130.

Blauert J (1983) Spatial hearing: the psychophysics of human sound localization. Cambridge, MA: MIT Press.

Brugge JD, Dubrowsky NA, Aitkin LM, Anderson DJ (1969) Sensitivity of single neurons in auditory cortex of cat to binaural tonal stimulation; effects of varying interaural time and intensity. J Neurophysiol 32:1005-1024.

Casagrande VA, Diamond IT (1974) Ablation study of the superior colliculus in the tree shrew (Tupaia glis). J Comp Neurol 156:207238.

Cowey A, Stoerig P (1991) The neurobiology of blindsight. Trends Neurosci 14:140-146.

Desimone R, Wessinger M, Thomas L, Schneider W (1990) Attentional control of visual perception: cortical and subcortical mechanisms. Cold Spring Harbor Symp Quant Biol 55:963-971.

du Lac S, Knudsen EI (1990) Neural maps of head movement vector and speed in the optic tectum of the barn owl. J Neurophysiol 63: 131-149.

Gardner MD (1969) Distance estimation of $0^{\circ}$ or apparent $0^{\circ}$-oriented speech signals in anechoic space. J Acoust Soc Am 45:47-53.

Grobstein P, Comer C, Kostyk SK (1983) Frog prey capture behavior: between sensory maps and directed motor output. In: Advances in vertebrate neuroethology (Evert $\mathrm{P}$, Capranica RR, Ingle D, eds), pp 331-347. New York: Plenum.

Heffner H, Heffner RS (1984) Temporal lobe lesions and perception of species-specific vocalizations by macaques. Science 226:75-76.

Heffner H, Heffner RS (1990) Effect of bilateral auditory cortex lesions on sound localization in Japanese macaques. J Neurophysiol 64:915931.

Heffiner H, Masterton B (1975) Contribution of auditory cortex to sound localization in the monkey (Macaca mulatta) J Neurophysiol 38:1340-1358.

Hikosaka O, Wurtz RH (1985) Modification of saccadic eye movements by GABA-related substances. I. Effect of muscimol and bicuculline in monkey superior colliculus. J Neurophysiol 53:266-291.

Hirsch JA, Chan JCK, Yin TCT (1985) Responses of neurons in the cat's superior colliculus to acoustic stimuli. I. Monaural and binaural response properties. J Neurophysiol 53:726-745.

Huerta MF, Harting JK (1982) Tectal control of spinal cord activity: neuroanatomical demonstration of pathways connecting the superior colliculus with the cervical spinal grey. In: Progress in brain research, Vol 57, Anatomy of descending pathways to the spinal cord (Kaypers HGJM, Martin GF, eds), pp 293-328. Amsterdam: Elsevier.

Huffman RF, Henson OW Jr (1990) The descending auditory pathway and acousticomotor systems: connections with the inferior colliculus. Brain Res Rev 15:295-323.

Imig TJ, Adrian HO (1977) Binaural columns in the primary field (A1) of cat auditory cortex. Brain Res 138:241-257.

Ingle DJ, Sprague JM (1975) Sensorimotor functions of the midbrain tectum. Neurosci Res Prog Bull 13:173-288.

Jay MF, Sparks DL (1984) Auditory receptive fields in primate superior colliculus shift with changes in eye position. Nature 309:345347.

Jenkins WM, Masterton RB (1982) Sound localization: effects of unilateral lesions in central auditory system. J Neurophysiol 47:9871016. 
Jenkins WM, Merzenich MM (1984) Role of cat primary auditory cortex for sound-localization behavior. J Neurophysiol 52:819-847.

Kavanagh GL, Kelly JB (1987) Contribution of auditory cortex to sound localization by the ferret (Mustelaputorius). J Neurophysiol 57: $1746-1766$.

Kelly JB (1980) Effects of auditory cortical lesions on sound localization by the rat. J Neurophysiol 44:1161-1174.

King AJ, Hutchings ME (1987) Spatial response properties of acoustically responsive neurons in the superior colliculus of the ferret: a map of auditory space. J Neurophysiol 57:596-624.

King AJ, Palmer AR (1983) Cells responsive to free-field auditory stimuli in guinea-pig superior colliculus: distribution and response properties. J Physiol (Lond) 342:361-381.

Knudsen EI (1982) Auditory and visual maps of space in the optic tectum of the owl. J Neurosci 2:1177-1 194 .

Knudsen EI (1983) Subdivisions of the inferior colliculus in the barn owl (Tyto alba). J Comp Neurol 218:174-186.

Knudsen EI (1984a) Synthesis of a neural map of auditory space in the owl. In: Dynamic aspects of neocortical function. (Edclman GM, Cowan WM, Gall WE, eds), pp 375-396. New York: Wiley.

Knudsen EI (1984b) Auditory properties of space-tuned units in the owl's optic tectum. J Neurophysiol 52:709-723.

Knudsen EI (1985) Experience alters the spatial tuning of auditory units in the optic tectum during a sensitive period in the barn owl. J Neurosci 5:3094-3109.

Knudsen EI, Brainard MS (1991) Visual instruction of the neural map of auditory space in the developing optic tectum. Science 253:85-87.

Knudsen EI, Knudsen PF (1983) Space-mapped auditory projections from the inferior colliculus to the optic tectum in the barn owl ( $T y t o$ alba). J Comp Neurol 218:187-196.

Knudsen EI, Konishi M (1978) A neural map of auditory space in the owl. Science 200:795-797.

Knudsen EI, Konishi M, Pettigrew JD (1977) Receptive fields of auditory neurons in the owl. Science 198:1278-1280.

Knudsen EI, Blasdel GG, Konishi M (1979) Sound localization by the barn owl measured with the search coil technique. J Comp Physiol 133:1-11.

Knudsen EI, Esterly SD, du Lac S (1991) Stretched and upside-down maps of auditory space in the optic tectum of blind-reared owls acoustic basis and behavioral correlates. J Neurosci 11:1727-1747.

Lee C, Rohrer WH, Sparks DL (1988) Population coding of saccadic eye movements by neurons in the superior colliculus. Nature 332: 357-360.

Leichnetz GR, Spencer RF, Hardy SGP, Astruc J (1981) An anatomical view of the role of the cortex in eye movement: projection from the prefrontal cortex to the superior colliculus and oculomotor complex in the monkey. In: Progress in oculomotor research, Vol 12, developments in neuroscience (Fuchs AF, Becker W, eds), pp 177184. Amsterdam: Elsevier.

Makous JC, Middlebrooks JC (1990) Two-dimensional sound localization by human listeners. J Acoust Soc Am 87:2188-2200.

McIlwain JT (1973) Topographic relationships in the projection from striate cortex to superior colliculus of the cat. J Neurophysiol 43:690701.

McIlwain JT (1986) Fffects of eye position on saccades evoked electrically from superior colliculus of alert cats. J Neurophysiol 55:97112.

Mcrcdith MA, Nemitz JW, Stein BE (1987) Determinants of multisensory integration in superior colliculus neurons. I. Temporal factors. J Neurosci 7:3215-3229.

Middlebrooks JC, Knudsen EI (1984) A neural code for auditory space in the cat's superior colliculus. J Neurosci 4:2621-2634.

Middlebrooks JC, Dykes RW, Merzenich MM (1980) Binaural response-specific bands in primary auditory cortex (AI) of the cat: topographical organization orthogonal to isofrequency contours. Brain Res 181:31-48.

Neff WD, Diamond IT, Casseday JH (1975) Behavioral studies of auditory discrimination: central nervous system. In: Handbook of sensory physiology, Vol 2 (Keidel, Neff WD, eds), pp 307-400. New York: Springer.

Olsen JF, Knudsen EI, Esterly SD (1989) Neural maps of interaural time and intensity differences in the optic tectum of the barn owl. J Neurosci 9:2591-2605.

Petersen SE, Fox PT, Posner MI, Mintun M, Raichle ME (1988) Positron emission tomographic studies of the cortical anatomy of singleword processing. Nature 331:585-589.

Phillips DP, Farmer ME (1990) Acquired word deafness, and the temporal grain of sound representation in the primary auditory cortex. Behav Brain Res 40:85-94.

Posner MI, Petersen SE (1990) The attention system of the human brain. Annu Rev Neurosci 13:25-42.

Powell TPS, Cowan WM (1961) The thalamic projection upon the telencephalon in the pigeon (Columba livia). J Anat (Lond) 95:78109.

Rafal RD, Posner MI, Friedman JH, Inhoff AW, Bernstein E (1988) Orienting of visual attention in progressive supranuclear palsy. Brain $111 \cdot 267-280$

Ravizza R, Diamond IT (1974) Role of auditory cortex in sound localization: a comparative ablation study of hedgehog and bushbaby. Fcd Proc 33:1917-1919.

Ravizza RJ, Masterton RB (1972) Contribution of neocortex to sound localization in the opossum (Didelphis virginiana). J Neurophysiol 35:344-356.

Riquimaroux H, Gaioni SJ, Suga N (1991) Cortical computational maps control auditory perception. Science 251:565-568.

Robinson DA (1972) Eye movements evoked by collicular stimulation in the alert monkey. Vision Res 12:1795-1808.

Sanchez-Longo LP, Forster FM (1958) Clinical significance of impairment of sound localization. Neurology 8:119-125.

Schiller PH, True S, Conway J (1980) Deficits in eye movements following frontal eye field and superior colliculus ablations. J Neurophysiol 44:1175-1189.

Schiller PH, Sandell JH, Maunsell JHR (1987) The effect of frontal eye field and superior colliculus lesions on saccadic latencies in the rhesus monkey. J Neurophysiol 57:1033-1048.

Schneider GE (1969) Two visual systems. Science 163:895-902.

Sprague JM (1991) The role of the superior colliculus in facilitating visual attention and form perception. Proc Natl Acad Sci USA 88: $1286-1290$.

Sprague JM, Meikle TH Jr (1965) The role of the superior colliculus in visually guided behavior. 11:115-146.

Stein BE (1988) Superior colliculus-mediated visual behaviors in cat and the concept of two corticotectal systems. In: Progress in brain research, Vol 75 (Hicks TP, Benedek G, eds), pp 37-53. Amsterdam: Elsevier.

Stein BE, Meredith MA, Huneycutt WS, McDade L (1989) Behavioral indices of multisensory integration: orientation to visual cues is affected by auditory stimuli. J Cognit Neurosci 1:1-12.

Suga N (1990) Cortical computational maps for auditory imaging. Neural Networks 3:3-21.

Sutter ML, Schreiner SE (1991) Physiology and topography of neurons with multipeaked tuning curves in cat primary auditory cortex. J Neurophysiol 65:1207-1226.

Thompson GC, Masterton RB (1978) Brain stem auditory pathways involved in reflexive head orientation to sound. J Neurophysiol 41 : 1183-1202.

Trevarthen C (1970) Experimental evidence for a brain stem contribution to visual perception in man. Brain Behav Evol 3:338-352.

Tunkl JE (1980) Location of auditory and visual stimuli in cats with superior colliculus ablations. Exp Neurol 68:395-402.

Wagner H (1993) Sound-localization deficits induced by lesions in the barn owl's auditory space map. J Neurosci 13:371-386.

Wagner H, Takahashi T, Konishi M (1987) Representation of interaural time difference in the central nucleus of the barn owl's inferior colliculus. J Neurosci 7:3105-3116.

Wurtz RH, Goldberg ME (1972) Activity of superior colliculus in behaving monkey. II. Effect of attention on neuronal responses. J Neurophysiol 35:560-574.

Zatorre RJ, Evans AC, Meyer E, Gjedde A (1992) Lateralization of phonetic and pitch discrimination in speech processing. Science 256 : 846-849. 